Sādhanä, Vol. 19, Part 5, October 1994, pp. 785-816. (C) Printed in India.

\title{
Finite element analysis of internal flows with heat transfer
}

\author{
M SRINIVAS $^{1}$, M S RAVISANKAR $^{1+}$, K N SEETHARAMU $^{1}$ and \\ P A ASWATHANARAYANA ${ }^{2 \checkmark}$ \\ ${ }^{1}$ Department of Mechanical Engineering, and \\ ${ }^{2}$ Department of Applied Mechanics, Indian Institute of Technology, \\ Madras 600036, India \\ ${ }^{+}$Present address: Department of Mechanical Engineering, Texas A\&M \\ University, USA
}

\begin{abstract}
This paper presents a finite element-based model for the prediction of 2-D and 3-D internal flow problems. The Eulerian velocity correction method is used which can render a fast finite element code comparable with the finite difference methods. Nine different models for turbulent flows are incorporated in the code. A modified wall function approach for solving the energy equation with high Reynolds number models is presented for the first time. This is an extension of the wall function approach of Benim and Zinser and the method is insensitive to initial approximation. The performance of the nine turbulent models is evaluated by solving flow through pipes. The code is used to predict various internal flows such as flow in the diffuser and flow in a ribbed channel. The same Eulerian velocity correction method is extended to predict the 3-D laminar flows in various ducts. The steady state results have been compared with benchmark solutions and the agreement appears to be good.
\end{abstract}

Keywords. Finite element method; internal flows; Eulerian velocity correction method; diffuser flow; inlet velocity distortion; heat transfer augmentation; 3-D laminar flows; flow through ducts; turbulence models.

\section{Introduction}

Internal flows, such as the flow through straight and curved ducts, cascades, diffusers, nozzles, combustion chambers, turbomachinery stators and rotors are among the most complex flows encountered in practice. The fluid dynamics and heat transfer behaviour of laminar and turbulent flows in channels and ducts are of interest because of wide applications in heat exchangers. The analysis of the hydrodynamics and heat transfer for flow in non-circular ducts is generally more complicated than in the case of circular pipe flow. For example the determination of developing flow, prediction of local and fully developed friction factors and Nusselt number requires a threedimensional analysis.

Most flows of technological interest are turbulent, at least in some regions. For 
many of these flows, relatively simple prediction methods suffice to produce results of engineering accuracy. Turbulence is one of the least understood phenomenon in fluid dynamics. The boundary layer in the earth's atmosphere, water currents below the surface of oceans, flow of water in rivers and canals, flow of fluids in heat exchangers and most combustion processes are some examples of turbulent flows.

Heat transfer augmentation studies in internal geometries with obstructions are of great relevance to the design of heat exchangers. For example, a two-dimensional flow over parallel ribs mounted on the surface of tubes or plates gives rise to separation and recirculation of the flow, which promote turbulent mixing and thereby enhance the rate of heat transfer. These advantages may be offset by an increase in pressure drop, with consequent increase in pumping power. The ability to predict these flows would, therefore, assist in optimizing the design of these devices.

Interest in heat exchanger surfaces with a high ratio of heat transfer area to core volume, as in the case of compact heat exchangers, is increasing at an accelerated pace. Because of the smaller flow passage hydraulic radius the heat exchanger design range usually falls well within laminar flow regime. A common understanding is that turbulent flows provide high heat transfer coefficients and hence are desirable in heat exchanger applications. Laminar flow heat exchangers can also offer substantial weight, volume, space and cost savings. Hence the knowledge of fluid friction and heat transfer in ducts of various flow cross-section geometries is important. In addition to compact heat exchangers, applications of laminar flow theory are also of interest in the aerospace, nuclear, biomedical, electronics and instrumentation fields.

Finite element method (FEM) is capable of handling complex geometries with ease and it is versatile in dealing with the mixed boundary conditions. FEM has an enviable generality in its approach. However, it is not as fast as finite difference techniques due to its lengthy assembly procedure. Attention is focussed on an algorithm which can render a fast finite element code in this work. Heat transfer augmentation by introducing obstructions in the flow path can be studied conveniently using FEM. Thus different types of obstructions with complicated shapes can be easily investigated.

The present work is aimed at predicting internal two- and three-dimensional flows. General purpose finite element codes for 2-D and 3-D have been developed. Nine different turbulence models have been incorporated in the code for the prediction of turbulent flows in 2-D.

The 2-D code is developed for axisymmetric geometries. It can also be used to solve plane problems with a simple idea. A straight line is nothing but part of a circle whose radius tends to infinity. A plane problem can also be viewed as an axisymmetric problem whose axis of symmetry lies far away, in principle, at infinite distance. Numerically infinity can be specified only as a big number. Hence by shifting the value of radial coordinate by a large number, the accuracy of calculation will not be affected. This approach is a valid short cut for solving a plane problem with a code for axisymmetric geometry without altering the code. The 3-D laminar code is developed in Cartesian coordinates.

\section{Survey of previous work}

\subsection{Turbulent flows}

Turbulent flows are characterized by their randomness. The diffusivity of turbulence, which causes rapid local mixing and increased rates of momentum, heat and mass 
transfer, is another important feature of turbulent flows. Although the Navier-Stokes equations have been assumed to apply in principle, equally to laminar and turbulent flows, the character of the small-scale details of turbulence prevents a complete analysis when using the present day computers. In order to achieve approximate solutions turbulent flow is often described in terms of averaged quantities. The process of averaging, however, necessitates the appearance of fluctuating velocities in conservative equations. No direct way of knowing the magnitudes of these terms is currently available. This leads to the well-known turbulence closure problem. To overcome this difficulty various turbulence models have been proposed.

A good number of review articles on modelling and computer simulation of turbulent flows is available in the literature (Mellor \& Herring 1973; Reynolds 1978, pp. 193-231; Bradshaw et al 1981; Haines 1982; Johnson \& Launder 1982; Launder 1982; Rodi 1982, 1984; Lumley 1983; Ferziger 1987; Hussaini \& Zang 1987; Hutton \& Smith 1987, pp. 289-310; Nallasamy 1987; Deissler 1988, pp. 1153-81; Markatos 1988, pp. 1221-75; Murphy 1988, pp. 1131-51; Lakshminarayana et al 1989). Nallasamy (1987) gives an excellent review of turbulent flows in internal geometries. Finite element simulation of turbulent flow is discussed at length by Hutton $\&$ Smith (1987, pp. 289-310).

One-point turbulence closure models are the most popular ones among all levels of turbulence modelling. These models are based on the averaging of Navier-Stokes equations. There are different levels of complexity in one-point closure, ranging from mixing length models to stress equation models. Many review papers give an extensive introduction to the models coming under one-point closure (Mellor \& Herring 1973; Rodi 1982, 1984; Ferziger 1987; Nallasamy 1987; Markatos 1988, pp. 1221-75; Murphy 1988, pp. 1131-51).

All the one-point closures are valid only in the fully turbulent regions. These models neglect the effect of molecular viscosity in comparison with the eddy viscosity. Such an assumption is valid only in fully turbulent regions. There are two distinct approaches to overcome this drawback. The wall function method is also called the high $\mathrm{Re}$ version models, while the other one, incorporating damping functions in the model, is also called the low $\mathrm{Re}$ version of the turbulence models. In the present code both high and low $\operatorname{Re}$ versions of $k-1, k-\varepsilon$ and $q-f$ models have been incorporated.

\subsection{Turbulent heat transfer modelling}

The current status of turbulent heat transfer is reviewed well by Launder $(1984,1988)$. Pletcher (1988) focusses the attention of his review on forced convection heat transfer. The reviews by Michelic \& Wingerath (1988, pp. 1393-1428), Patankar (1988) and Shih $(1985,1987,1989)$ give an overall picture of the heat transfer research. The present work confines itself to forced convection heat transfer, where heat is treated as a passive scalar. The wall function methods used to specify the velocity at the wall layer (Benim \& Zinser 1985), for the high Re version of the models are utilised for the specification of temperature also for the first time. A wall heat flux temperature $T_{*}$ is defined on similar lines to $U_{*}$.

\subsection{3-Dimensional laminar flows}

Although a large number of numerical methods have been proposed with the progress in computers, the transient 3-D analysis of flow remains a difficult task due to the 
enormous amount of computational storage and effort required. The explicit time integration scheme has the advantage of saving computational storage owing to mass lumping. The implicit time integration scheme is reported to be more stable than the explicit scheme but the inversion and storage of large matrices are required.

With the advent of modern electronic computers, several different finite-different formulations of the steady-state, three-dimensional Navier-Stokes equations have been investigated. Difficulties in imposition of the pressure boundary conditions and satisfaction of the continuity equation are encountered in the primitive variables approach. General numerical marching procedures for the calculation of the transport processes in three-dimensional ducts have been proposed by Caretto et al (1972) and Curr et al (1972).

Gresho et al (1981) developed a finite element program for the time-dependent solution of the 3-D Navier-Stokes equations. The model is based on the Galerkin approximation of the primitive variable formulation of the Navier-Stokes equations. Reddy (1982) presented results of a penalty finite element analysis for three-dimensional incompressible flows in enclosures.

In the present study, a general purpose finite element code for full Navier-Stokes equation to predict the recirculating flows is developed. The explicit time-integration scheme is used to save computer storage and computational time.

\section{Fractional step methods}

There are a variety of fractional step methods which can be obtained by appropriately combining the pressure, viscous and the convective terms in the equations. Ferziger (1987) gives an excellent review on the different numerical schemes available. Ravikumaur (1988) uses a fully explicit scheme with mass lumping of the matrices. Mass lumping of the matrices and explicit scheme render a well matched technique (Donea et al 1982). Mass lumping shifts the frequency downwards and the explicit scheme upwards, thereby each balancing the other. Reduced order integration is used for pressure (Smith 1984; Benim \& Zinser 1985; Autret et al 1987; Gresho \& Sani 1987; Utnes 1988). Ravikumaur (1988) uses equal-order interpolation with the Eulerian velocity correction scheme. Chequer-board splitting (or spurious pressure oscillations) is a ubiquitous phenomenon. Averaging the pressure field is often resorted to for presenting the results. Specification of the pressure boundary condition is well discussed in Gresho \& Sani (1987). Traction-free exit boundary condition is often preferred.

\subsection{Governing equations}

The non-dimensionalised governing equations for unsteady-state incompressible flow are given below. The index $j$ is 3 for 3-D equations and 2 for 2-D problems. For 2-D plane problems $X_{2}$ becomes very large and its contribution is thus negligible. Also the equations should be read without $X_{2}$ for 3-D problems.

Continuity equation

$$
\frac{1}{X_{2}}\left[\frac{\partial\left(X_{2} U_{i}\right)}{\partial X_{i}}\right]=0 .
$$


Momentum equations (In $X_{i}$ direction)

$$
\begin{aligned}
\frac{\partial U_{i}}{\partial t}+U_{j} \frac{\partial U_{i}}{\partial X_{j}}=\frac{\partial P}{\partial X_{i}}+\frac{1}{X_{2}} \frac{\partial}{\partial X_{j}}\left[X_{2}\left(\frac{1+v_{T}}{\operatorname{Re}}\right)\right. & \left.\left(\frac{\partial U_{i}}{\partial X_{j}}+\frac{\partial U_{j}}{\partial X_{i}}\right)\right] \\
& -\delta_{i, 2} \frac{2 U_{i}}{X_{2}^{2}}\left(\frac{1+v_{T}}{\operatorname{Re}}\right)
\end{aligned}
$$

for $j=1,2,3$,

where $P$ is pressure and $v_{T}$ is turbulent momentum diffusivity. This is zero for laminar flow problems. Appropriate reference values of velocity $U_{\text {ref }}$ and length $L_{\text {ref }}$ along with the kinematic viscosity $v$, density $\rho$ and thermal diffusivity $\alpha$ are used so that the variables are dimensionless. Time is non-dimensionalised by $L_{\text {ref }} / U_{\text {ref }}$.

Reynolds number is defined by

$$
\operatorname{Re}=U_{\text {ref }} \times L_{\text {ref }} / v
$$

Energy equation

$$
\frac{\partial T}{\partial t}+U_{i} \frac{\partial T}{\partial X_{i}}=\frac{1}{X_{2}} \frac{\partial}{\partial X_{i}}\left[X_{2}\left(\frac{1+\alpha_{T}}{\mathrm{Pe}}\right)\left(\frac{\partial T}{\partial X_{i}}\right)\right]
$$

where $\alpha_{T}$ is turbulent thermal diffusivity which is zero for laminar flow problems, and $P e$ is Peclet number.

Even though nine models are used to study the flow through the pipe, only the details of $k-\varepsilon$ model are given which is widely reported in literature. Lam \& Bremhorst (1981) damping is used for low Re version of $k-\varepsilon$ model.

$k-\varepsilon$ model: The turbulent momentum diffusivity is obtained through the solution of two partial differential equations. Lam \& Bremhorst's (1981) model is used. $k$ is non-dimensionalised by $U_{\text {ref }}^{2}$ and $\varepsilon$ by $U_{\text {ref }}^{3} / L_{\text {ref }}$.

k equation:

$$
\frac{\partial k}{\partial t}+U_{i} \frac{\partial k}{\partial X_{i}}-\frac{1}{X_{2}} \frac{\partial}{\partial X_{j}}\left[X_{2} \frac{1}{\operatorname{Re}}\left(1+\frac{v_{T}}{\sigma_{k}}\right)\left(\frac{\partial k}{\partial X_{j}}\right)\right]-Q_{k}=0
$$

where $Q_{k}$ is the source term given by

$$
Q_{k}=v_{T} \frac{\partial U_{i}}{\partial X_{j}}\left[\frac{\partial U_{i}}{\partial X_{j}}+\frac{\partial U_{j}}{\partial X_{i}}\right]-\varepsilon
$$

E equation:

$$
\frac{\partial \varepsilon}{\partial t}+U_{i} \frac{\partial \varepsilon}{\partial X_{i}}-\frac{1}{X_{2}} \frac{\partial}{\partial X_{j}}\left[X_{2} \frac{1}{\operatorname{Re}}\left(1+\frac{v_{T}}{\sigma_{\varepsilon}}\right)\left(\frac{\partial \varepsilon}{\partial X_{j}}\right)\right]-Q_{\varepsilon}=0
$$

where $Q_{E}$ is the source term given by

$$
Q_{\varepsilon}=C_{\mu} C_{\varepsilon 1} f_{\mu} f_{1} k \frac{\partial U_{i}}{\partial X_{j}}\left[\frac{\partial U_{i}}{\partial X_{j}}+\frac{\partial U_{j}}{\partial X_{i}}\right]-C_{\varepsilon 2} f_{2} \varepsilon^{2} / k
$$


$C_{\mu}, C_{\varepsilon 1}, C_{\varepsilon 2}, \sigma_{k}$ and $\sigma_{\varepsilon}$ are constants equal to $0.09,1.44,1.92,1.0$ and 1.3 respectively. The damping functions $f_{\mu}, f_{1}$ and $f_{2}$ are given by

$$
\begin{aligned}
& f_{\mu}=\left(1-\exp \left(-0.0165 \operatorname{Re}_{k}\right)\right)^{2}\left(1+20.5 / \operatorname{Re}_{T}\right), \\
& f_{1}=1+\left(0.05 / f_{\mu}\right)^{3}, \\
& f_{2}=1-\exp \left(-\operatorname{Re}_{T}^{2}\right) .
\end{aligned}
$$

$\operatorname{Re}_{T}$ and $\operatorname{Re}_{k}$ are defined by the following equations

$$
\begin{aligned}
& \operatorname{Re}_{T}=\operatorname{Re} k^{2} / \varepsilon, \\
& \operatorname{Re}_{k}=\operatorname{Rek} k^{0.5} \cdot y .
\end{aligned}
$$

Turbulent momentum diffusivity is then calculated by

$$
v_{T}=\operatorname{Re} f_{\mu} C_{\mu} k^{2} / \varepsilon .
$$

\subsection{Method of solution}

The Eulerian velocity correction method, a solution algorithm for unsteady, incompressible Navier-Stokes equations, is used to solve the momentum equations. Solution is advanced in three steps within every time step. The three steps involved are calculation of pseudo velocities, calculation of pressure from the Poisson equation and correction of pseudo-velocities to obtain velocities at the next time step.

Step 1. Calculation of pseudo velocities: The pseudo velocities $V_{i}$ are calculated from (2) by dropping the pressure terms. Since these velocities will not satisfy the continuity equation, they are known as pseudo velocities.

$$
\begin{aligned}
\frac{\partial V_{i}}{\partial t}=-U_{j} \frac{\partial U_{i}}{\partial X_{j}}+\frac{1}{X_{2}} \frac{\partial}{\partial X_{j}}[ & \left.X_{2}\left(\frac{1+v_{T}}{\operatorname{Re}}\right)\left(\frac{\partial U_{i}}{\partial X_{j}}+\frac{\partial U_{j}}{\partial X_{i}}\right)\right] \\
& -\delta_{i, 2} \frac{2 U_{i}}{X_{2}^{2}}\left(\frac{1+v_{T}}{\operatorname{Re}}\right), \text { for } j=1,2,3 .
\end{aligned}
$$

An explicit Euler's scheme is used to expand the time derivative of the above equation in the time domain,

$$
\frac{\partial V_{i}}{\partial t}=\frac{V_{i}^{n+1}-U_{i}^{n}}{\Delta t^{n}} .
$$

From (15) and (16) pseudo velocity $V_{i}$ can be calculated.

Step 2. Pressure Poisson equation: By modifying (2) and (15), the following equation is obtained,

$$
\frac{\partial U_{i}}{\partial t}-\frac{\partial V_{i}}{\partial t}=-\frac{\partial P}{\partial X_{i}} .
$$


Both the time derivatives are expanded explicitly,

$$
\frac{\partial P^{n+1}}{\partial X_{i}}=\frac{V_{i}^{n+1}-U_{i}^{n+1}}{\Delta t^{n}}
$$

Taking the partial derivative of (18) with respect to $X_{i}$ and after some modification, the following pressure Poisson equation is obtained,

$$
\frac{1}{X_{2}}\left[X_{2} \frac{\partial^{2} P^{n+4}}{\partial^{2} X_{i}}\right]=\frac{1}{X_{2}} \frac{1}{\Delta t^{n}}\left(\frac{\partial\left(X_{2} V_{i}^{n+1}\right)}{\partial X_{i}}\right)
$$

Step 3. Velocity correction: The original velocities of the next time step $U_{i}^{n+1}$ are obtained by correcting the pseudo velocities using the evaluated pressure field

$$
U_{i}^{n+1}=V_{i}^{n+1}-\Delta t^{n}\left(\partial P^{n+1} / \partial X_{i}\right)
$$

Some of the advantages of the present scheme are - the pressure Poisson equation alone is solved from a set of algebraic equations. In steps 1 and 3 mass lumping is done which makes the stiffness matrix diagonal. The inverse of the diagonal matrix is just the inverse of each element which saves the computational time. The explicit scheme tends to shift the frequency of oscillation up and the mass lumping procedure shifts it down. Hence the combination of these two will result in a well-matched scheme. The stiffness matrix in the Poisson equation does not depend on anything that evolves with time and hence the assembly procedure is done only once in the first iteration.

The solution of the partial differential equation is sought using the finite element method. The Galerkin weighted-residual technique is used to formulate the problem. Benim \& Zinser (1985) have reported that linear elements are preferable to higher order elements for turbulent flow problems. Based on their suggestion, linear triangular elements in two-dimensional problems and tetrahydron elements for three-dimensional problems are used. Also triangular elements and tetrahedral elements do not require any numerical integration which again saves computational time.

\section{Results and discussion}

\subsection{2-D turbulent flows}

4.1a Developing flow through a smooth circular pipe: A circular pipe represents the simplest axisymmetric geometry. Turbulence modelling is not complete even in this geometry. Comparative study of different models of turbulence by the same code, for a particular problem under identical conditions, would throw unambiguous light on the strength and weakness of each model. In the present section, different models of turbulence are evaluated for their predictive capabilities. Both momentum and heat transfer are studied.

Taylor et al (1977) suggest the use of special elements with logarithmic shape functions near the wall to get better predictions. High Re versions of the model tend to give accurate results for this problem (Benim \& Zinser 1985; Morgan et al 1987; 
Taylor et al 1981, pp. 341-9). However, Martinuzzi \& Pollard (1989) conclude that the low $\operatorname{Re}$ version $k-\varepsilon$ model performs better than the high $\mathrm{Re}$ version model. Benim \& Zinser (1985) use the high $\mathrm{Re}$ version of the $k-\varepsilon$ model for their predictions. One of their important suggestions is the use of linear elements in favour of higher order elements. Taylor et al (1977) clearly bring out that in high Re version models, the initial assumption of wall shear stress is very crucial. The predictions are highly sensitive to the initial assumption. Benim \& Zinser (1985) suggest a brilliant approach, by which this problem can be completely obviated. In the present work, this approach is extended to heat flow prediction for all the boundary conditions. The conclusion of Martinuzzi \& Pollard (1989), that low Re models perform better is not true over a ränge of Reynolds number, particularly at high Reynolds numbers. The low $\mathrm{Re}$ model used by them, which is based on Lam \& Bremhorst (1981) damping, is known for its accurate prediction near the wall, especially at low Reynolds numbers (less than $10^{5}$ ).

(i) Geometry and boundary conditions - The developing length of turbulent flow in a pipe is approximateiy $30-50$ pipe diameters. Hence the length of the pipe is selected as 70 times the pipe diameter.

Inlet values of turbulent kinetic energy $k$ and its dissipation are specified based on Martinuzzi \& Pollard (1989). The turbulent intensity of the stream at the inlet is assumed to be $6 \%$, and a uniform $k$ profile is specified. The inlet condition of $\varepsilon$ is calculated from the following relationship.

$$
\varepsilon_{\mathrm{Ln}}=\left(C_{\mu} \cdot k^{3 / 2}\right) /(0 \cdot 015 \mathrm{D})
$$

(ii) Results and discussion-Table 1 compares the fully developed friction factor, Nusselt number and the centreline velocity. All the derivatives are calculated using the wall function approach. The comparison is shown for Reynolds number 100000 . Performance of the low Re version of the $q-f$ model is bad. In all other cases the error is well within the acceptable limit.

Table 1. Comparison of fully developed centre line velocity, friction factor and Nusselt number for flow through a smooth circular pipe at $\operatorname{Re}=100000$ and $\operatorname{Pr}=0 \cdot 71$.

\begin{tabular}{|c|c|c|c|c|c|c|}
\hline \multirow[b]{2}{*}{ Model } & \multicolumn{2}{|c|}{$U_{\mathbf{c L}}$} & \multicolumn{2}{|c|}{$C_{f}$} & \multicolumn{2}{|c|}{$N u$} \\
\hline & $\begin{array}{c}\text { Present } \\
\text { work }\end{array}$ & $\begin{array}{c}\text { Error }^{\dagger} \\
(\%)\end{array}$ & $\begin{array}{c}\text { Present } \\
\text { work }\end{array}$ & $\begin{array}{c}\text { Error }^{\ddagger} \\
(\%)\end{array}$ & $\begin{array}{c}\text { Present } \\
\text { work }\end{array}$ & $\begin{array}{c}\text { Error* } \\
(\%)\end{array}$ \\
\hline PML & $1 \cdot 150$ & $-5 \cdot 7$ & 0.0183 & 1.7 & 186 & $2 \cdot 0$ \\
\hline NML & 1.216 & -0.3 & 0.0169 & $-6 \cdot 1$ & 166 & -8.9 \\
\hline VEV & 1.242 & 1.8 & 0.0168 & $-6 \cdot 7$ & 163 & -10.6 \\
\hline$k-1$ (LR) & $1 \cdot 200$ & -1.6 & 0.0182 & $-1 \cdot 1$ & 186 & 2.0 \\
\hline$k-1$ (HR) & $1 \cdot 183$ & $-3 \cdot 0$ & 0.0173 & $-4 \cdot 2$ & 178 & $-2 \cdot 3$ \\
\hline$k-\varepsilon(\mathrm{LR})$ & $1 \cdot 190$ & $-2 \cdot 5$ & 0.0182 & $1 \cdot 1$ & 195 & $7 \cdot 0$ \\
\hline$k-\varepsilon$ (HR) & $1 \cdot 160$ & $-4 \cdot 9$ & 0.0176 & -2.5 & 180 & $-1 \cdot 3$ \\
\hline$q-f(\mathrm{LR})$ & $1 \cdot 120$ & $-8 \cdot 2$ & 0.0250 & 38.9 & 240 & $31 \cdot 7$ \\
\hline$q-f(\mathrm{HR})$ & $1 \cdot 160$ & -4.9 & 0.0190 & 5.6 & 197 & $8 \cdot 1$ \\
\hline
\end{tabular}

${ }^{\dagger}$ Compared with the fully developed value $1 \cdot 220$; ${ }^{\ddagger}$ Compared with the fully developed value 0.018; *Compared with the fully developed value $182 \cdot 30$ 


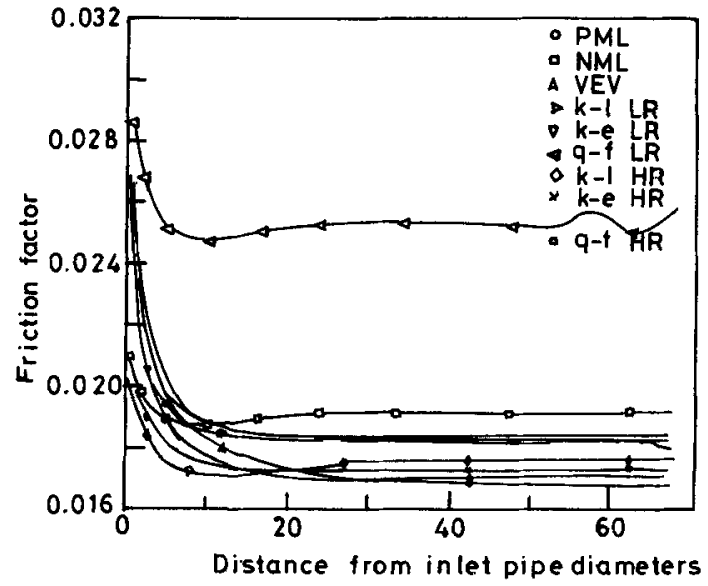

Figure 1. Comparison of friction factor for flow through a pipe at $\operatorname{Re}=100000$, for different turbulence models.

In the literature, only the high $\mathrm{Re}$ version of the $q, f$ model is available (Smith 1984). The high $\mathrm{Re}$ version of this model is often quoted for its numerical stability (Hutton \& Smith 1987, pp. 289-310). Hence an attempt to develop a low Re version is made. In the process of derivation a few terms are ignored, these terms are primarily responsible for the bad prediction of the $q-f$ model. The high Re version of $q-f$ model's performance indicates that the ignored terms are not important away from the wall. Tuning the damping constants will improve the results predicted by the $q-f$ model, as the values are only shifted numerically and the trends agree well with the behaviour of the other models.

Figure 1 also reveals another interesting feature. But for zero equation models, all the other models show a dip in the friction factor around 10 diameters from the entry. This observation coincides with the results of Benim \& Zinser (1985). This undershoot in the curve is not predicted by the zero equation models as they do not incorporate turbulent history in their prediction. As the boundary layer develops along the wall the central core is accelerated. When the flow is accelerated the turbulent kinetic energy decreases. This influences the prediction of the eddy viscosity. A decrease in eddy viscosity in turn decreases the friction factor, which is the cause of the undershoot of friction factor.

Figure 2 compares the fully developed profiles predicted using different models with the experimental results as in Ravisankar (1992). Fully developed turbulent kitetic energy profiles predicted by the high and low Re versions of $k-1, k-\varepsilon$ and $q-f$ models are compared with the experimental results of Lawn (vide Martinuzzi \& Pollard 1989 ) in figure 3. Low Re version $q-f$ model over-predicts turbulent kinetic energy. This is the reason for over-prediction of eddy viscosity, which in turn is responsible for the over-estimation of the skin friction coefficient.

The damping functions used in the models are not valid over a big range of Reynolds numbers. Most of them are valid only for Re less than 500000 . On the other hand the high Re version of the models can be applied only in the fully turbulent zones. Figure 4 shows the variation of $\mathrm{Nu}$ along the pipe length, predicted with different models. The trends are similar to the variation of friction factor. Especially the prediction of low $\operatorname{Re} q-f$ model indicates this clearly. Also the undershoot of $\mathrm{Nu}$ is similar to the undershoot of $C f$. 


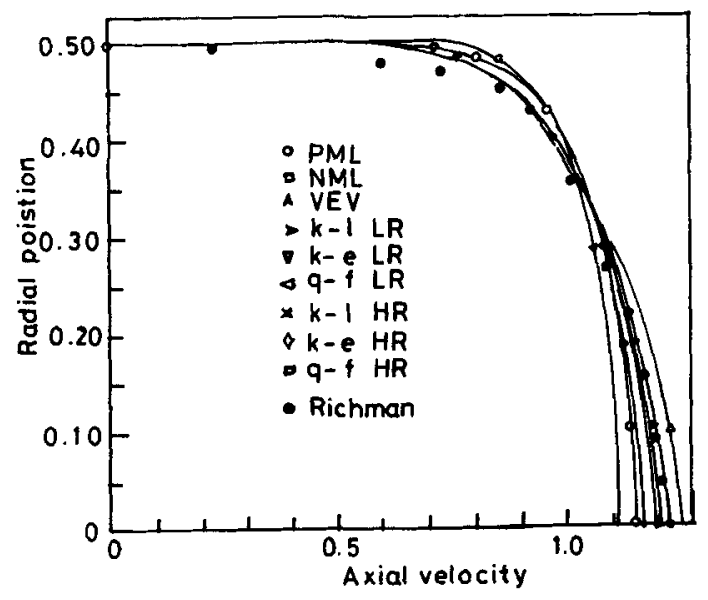

Figure 2. Comparison of fully developed velocity profile for flow through a pipe at $\operatorname{Re}=100000$, for different turbulence models.
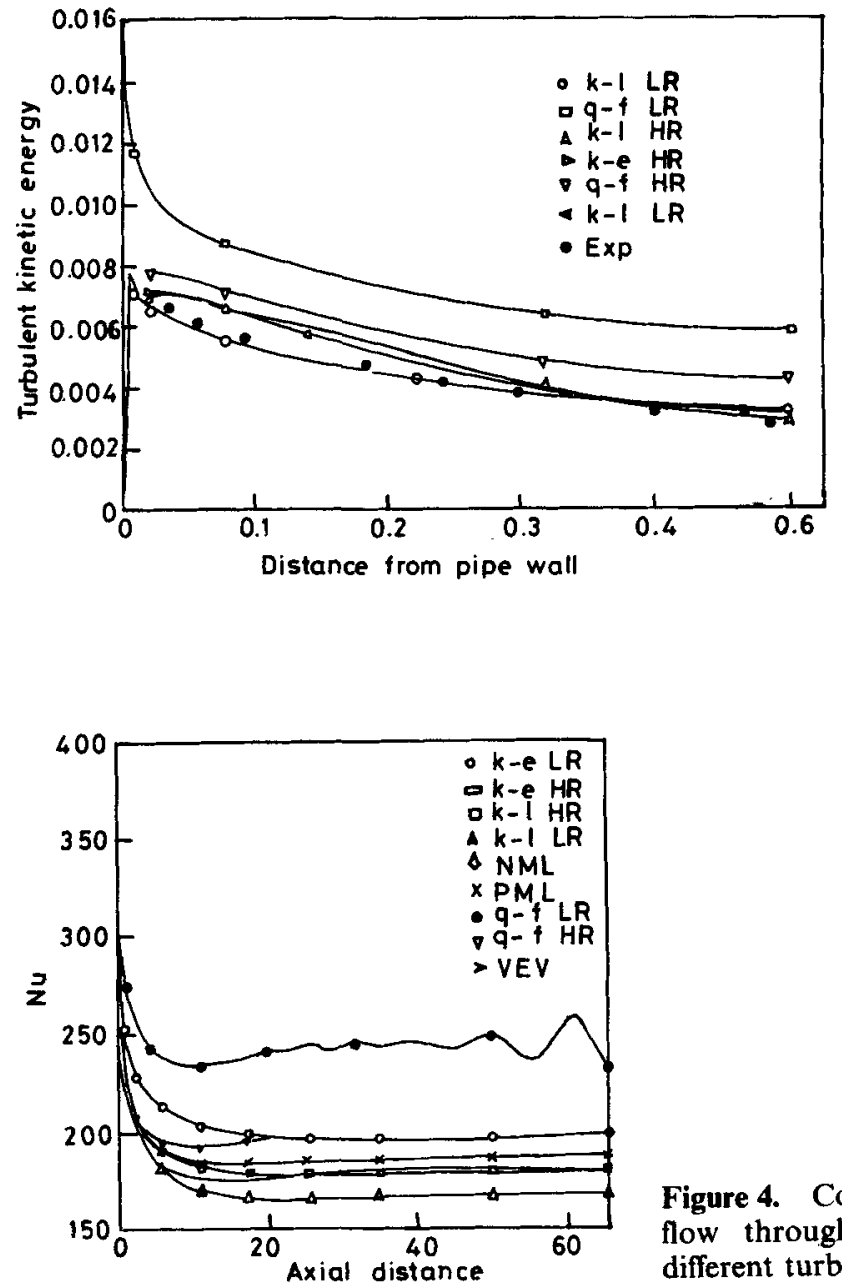

Figure 3. Comparison of fully developed turbulent kinetic energy profile for a flow through a pipe at $R e=100000$, for different turbulence models.

Figure 4. Comparison of Nusselt numbers for flow through a pipe at $R e=100000$, for different turbulence models. 
Table 2. Comparison of the number of iterations for convergence using $k-\varepsilon$ model with modified wall function approach for different initial distributions.

\begin{tabular}{llcc}
\hline $\begin{array}{l}\text { S. } \\
\text { No. }\end{array}$ & $\begin{array}{c}\text { Wall } \\
\text { boundary } \\
\text { Condition }\end{array}$ & $\begin{array}{c}\text { Initial } \\
\text { Temperature } \\
\text { distribution }\end{array}$ & $\begin{array}{c}\text { Iterations }^{\dagger} \\
\text { required for } \\
\text { convergence }\end{array}$ \\
\hline 1 & Temperature & $0 \cdot 0$ & 87 \\
2 & Temperature & $1 \cdot 0$ & 91 \\
3 & Heat flux & $0 \cdot 0$ & 95 \\
4 & Heat flux & $1 \cdot 0$ & 141 \\
\hline
\end{tabular}

${ }^{+}$Maximum error tolerable between two successive iterations is specified as $1 \times 10^{-7}$

One of the important contributions of the present work is the extension of the wall function approach of Benim \& Zinser (1985) to heat transfer prediction. This reduces the anxiety in specifying the initial temperature distribution at the wall layer. Table 2 gives the details about the number of iterations required for convergence for the correct values of two extreme conditions. A steady-state solver with high $\operatorname{Re} k-\varepsilon$ model is used to obtain the solution. The converged values are the same even though the assumptions of initial distributions are drastically different.

(iii) Conclusions - (1) The modified wall function approach for heat transfer prediction with high $\mathrm{Re}$ version of the models is successful. This approach is insensitive to the initial distribution of wall temperature.

(2) The predictions of low Re version of $q-f$ model are poor. The terms neglected in the process of derivation are found to be important near the wall.

(3) The one-equation $k-1$ model, displays excellent stability and the quality of predictions is good. This model is highly reliable for its performance. The only difficulty is the specification of the mixing length distribution for complex geometries.

(4) All the damping functions need critical examination. Invariably the low Re versions of the models fail at $\mathrm{Re}=500000$ and above.

4.1b Heat transfer augmentation in channels - effect of rib wall inclination: Channels with turbulence promoters such as ribs, fins and thin obstructions are used for heat transfer augmentation in heat exchangers. All the experiments show that the heat transfer coefficient increases by a factor of two in the vicinity of the reattachment point. The flow of cooling air in gas turbine blades can be approximated as the flow through a channel with two opposite rib roughened walls. The wall of the rib is generally made vertical for obtaining maximum mixing. However, slightly inclining the wall of the rib brings down the total pressure drop and results in better heat transfer augmentation efficiency.

Currently, a large number of technical papers are available for turbulent flow inside rib-roughened channels. However little attention is given to the shape of the rib. Han et al (1978) experimentally studied the effect of angle of attack, pitch ratio and rib shape on friction factor and heat transfer results. The shape of the rib was altered by filling modelling clay in the corners of the rectangular ribs instead of inclining the wall. The effects of rib shape on the pressure drop and heat transfer augmentation efficiency are not studied. 
A brief literature survey is summarized below. Liou et al (1990) presented mean velocity and turbulence intensity profiles for an arrangement of two pairs of turbulence promoters mounted in tandem in channel flow. The predictions are compared with experiments. Measured axial velocity and turbulent kinetic energy values are given as inlet conditions for the numerical predictions. The effect of pitch ratio and the influence of $\operatorname{Re}$ on the reattachment length are documented. It has been found experimentally that there are two major enhancement peaks, one located slightly downstream of the leading edge of the rib and the other 0.5 to 1.0 rib heights upstream of the reattachment point. Acharya et al (1993) used nonlinear and standard $k-\varepsilon$ models with wall functions for predicting the recirculation lengths and maximum Nusselt number locations and compared them with the experiments. Both models predicted reattachment lengths well but under-predicted local Nusselt numbers. This is attributed to inadequacies in wall functions. Also the Nusselt number peak near the leading edge of the rib is not predicted.

The Reynolds number based on hydraulic diameter of the channel is 85600 . The study is carried out with three pitch ratios (PR), 5, 10 and 15. The rib wall angles $(\theta)$ considered are 0,35 and 50 . The aim of the study is to investigate the variations in Nusselt number, friction factor, reattachment lengths and efficiency of heat transfer
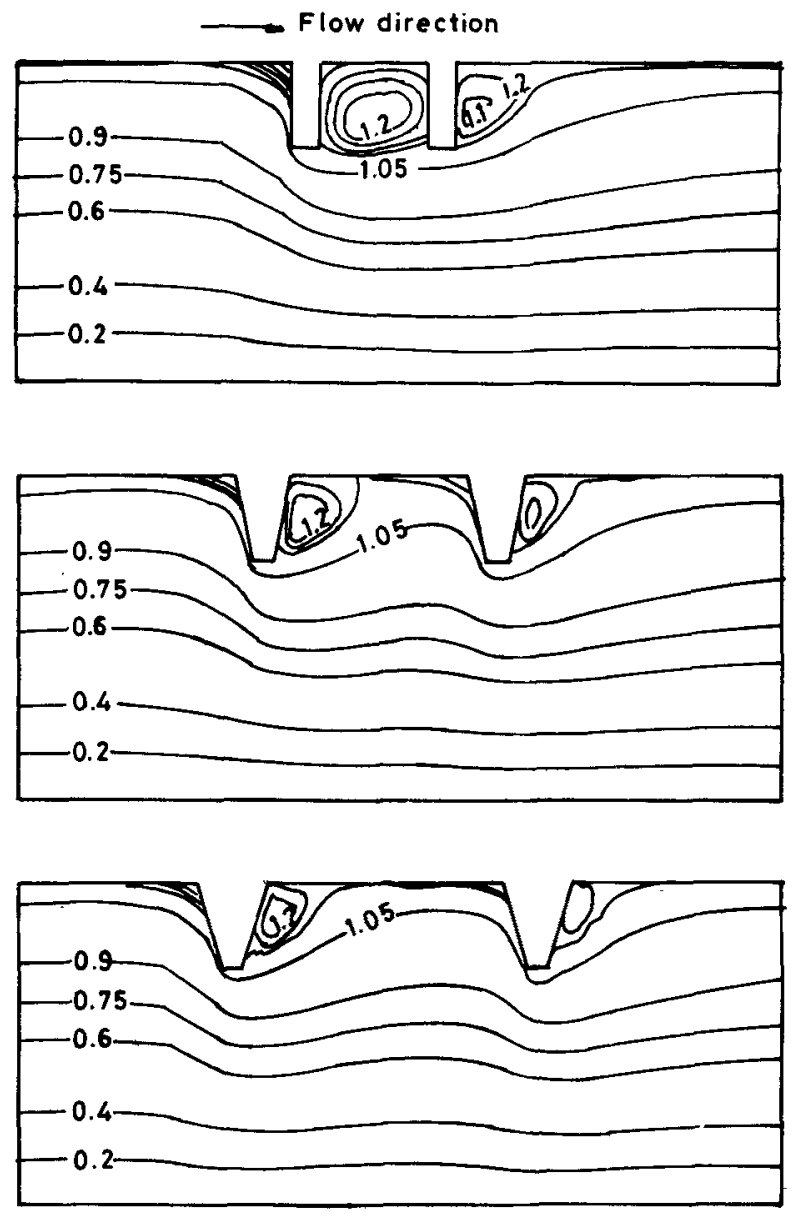

Figure 5. Stream-line plots for flow through ribbed channels for different pitch ratios and different rib-wall inclinations. 
Table 3. Comparison of reattachment length for turbulent flow through sudden pipe expansion.

\begin{tabular}{lllc}
\hline Inlet $k$ & Inlet $k$ & $\begin{array}{c}\text { Inlet } U \\
\text { profile }\end{array}$ & $\begin{array}{c}\text { Reattachment } \\
\text { length }\end{array}$ \\
\hline 0.16 & 0.23 & $1 / 7$ law & 6.10 \\
0.11 & 0.22 & $1 / 7$ law & 8.60 \\
0.06 & 0.0882 & 1/7 law & 10.10 \\
0.06 & 0.1633 & 1/7 law & 5.70 \\
0.06 & 0.0882 & Uniform & 8.90 \\
& & profile & \\
\hline
\end{tabular}

augmentation by varying the wall inclination and pitch ratios. The same geometry is used as in Liou et al (1990). The reattachment lengths are calculated from the trailing edge of the rib.

(i) Results and discussion - Figure 5, shows some typical stream line plots. As the rib wall inclination increases, the separation bubble became smaller.

The prediction of reattachment length is very sensitive to the inlet conditions of $k$ and $\varepsilon$. For the flow through a sudden pipe expansion the authors studied the effect of inlet conditions of $k$ and $\varepsilon$ and table 3 gives the prediction of reattachment lengths for $\operatorname{Re}=100000$ with $k-\varepsilon$ model. The experimental value for reattachment length for sudden expansion is around 8.5 to 9.0 step heights (Nallasamy 1987). These results clearly bring out the effect of inlet $k$ and $\varepsilon$ on the prediction of reattachment length. For the present study no comparison of reattachment length was done since the inlet $k$ and $\varepsilon$ are not given by Liou et al (1990).

Table 4 compares the reattachment lengths for various pitch ratios and step wall inclinations. The reattachment length after second step $X_{r 2}$ is around 3 in all the cases. The rib wall inclination has little effect on the $X_{r 2}$. Liou et al (1990) reported that $X_{r 2}$ remains almost constant for $5<P R<20$. For $\theta=0^{\circ}$ and $P R 10$ and 15 , the $X_{R 1}$ is almost double that of $X_{R 2}$.

Figures 6 and 7 compare the velocity profiles at three different sections for $P R=10$ and 15 . As the rib wall inclination increases the negative velocities and centre-line

Table 4. Values of $X_{R 1}$ and $X_{R 2}$.

\begin{tabular}{lrcc}
\hline$\theta$ & PR & $X_{R 1}$ & $X_{R 2}$ \\
\hline \multirow{3}{*}{0} & 5 & - & 3.026 \\
& 10 & 5.633 & 2.972 \\
& 15 & 5.953 & 3.119 \\
35 & 5 & - & 2.689 \\
& 10 & 3.540 & 2.542 \\
& 15 & 3.659 & 2.971 \\
50 & 5 & - & 2.649 \\
& 10 & 3.611 & 2.561 \\
& 15 & 3.746 & 2.756 \\
\hline
\end{tabular}




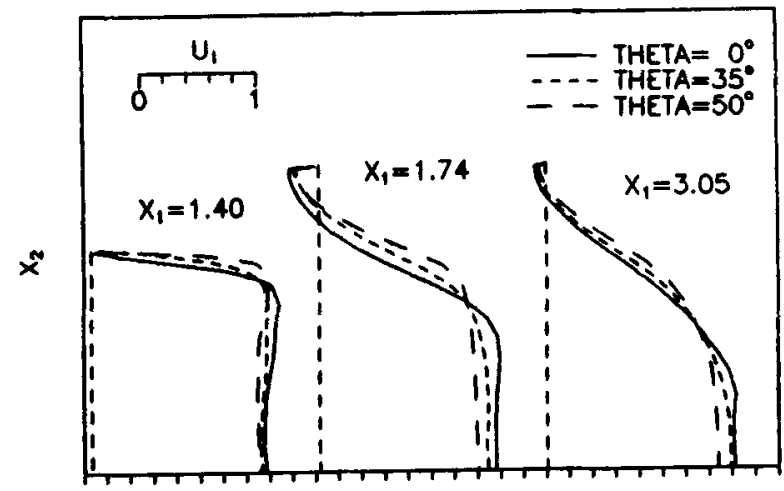

Axial Volocity

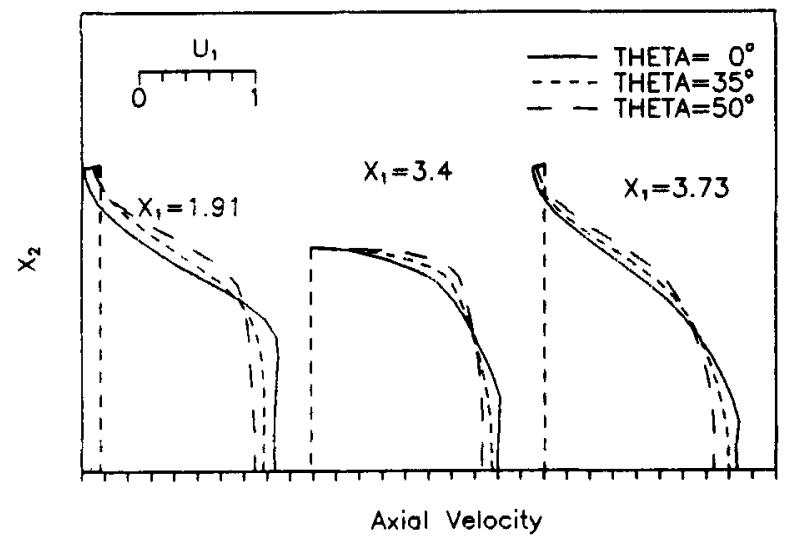

Figure 6. Comparison of axial velocity profiles at different locations for different $\theta$ and $P R=10$, for flow through ribbed channels.

Figure 7. Comparison of axial velocity profiles at different locations for different $\theta$ and $\mathrm{PR}=15$, for flow through ribbed channels.

velocities decrease. This explains the reduction in reattachment lengths. Similar flow distributions are found in all cases, downstream of the second rib. Further downstream, the flow eventually approaches that of the fully developed channel flow.

Figures 8 and 9 show the variations of turbulent kinetic energy profiles for PR $=10$ and 15. The value of turbulent kinetic energy in the centre region of the flow is almost zero. On the other hand, large values of $k$ are found in the flow separation region

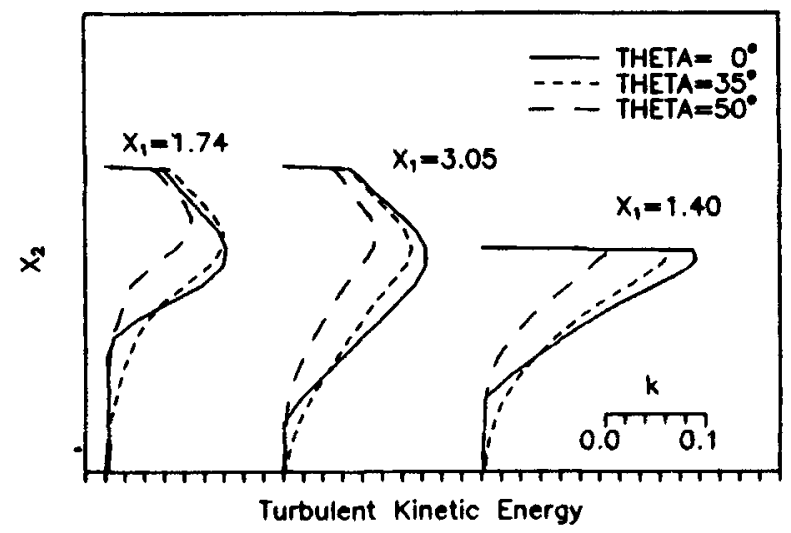

Figure 8. Comparison of turbulent kinetic energy profiles at different locations for different $\theta$ and $P R=10$, for flow through ribbed channels. 


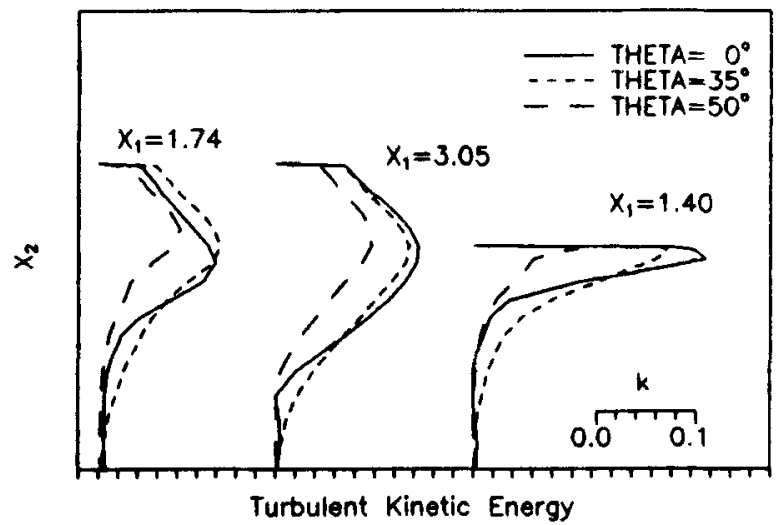

Figure 9. Comparison of turbulent kinetic energy profiles at different locations for different $\theta$ and $P R=15$, for flow through ribbed channels.

and the shear layers where high velocity gradients exist. As the angle $\theta$ increases, the peak value of turbulent kinetic energy reduces. This is due to the reduced mixing of the flow. Figure 10 shows the three-dimensional plot of turbulent kinetic energy for $\mathrm{PR}=10$ and $\theta=35^{\circ}$. The twa peaks in the plot correspond to the peak values of kinetic energy below two ribs.

Figures 11 and 12 show the Nusselt number peaks clearly. As was reported by Liou et al (1990) every step has two peaks, one just near the leading edge of the step and another 0.5 to 1.0 times the step height upstream of the reattachment point. It can be seen from these figures that both the peaks are predicted well in these cases. However, the peaks occurred at a distance of about 1 to 1.5 times the step height, upstream of the reattachment points.

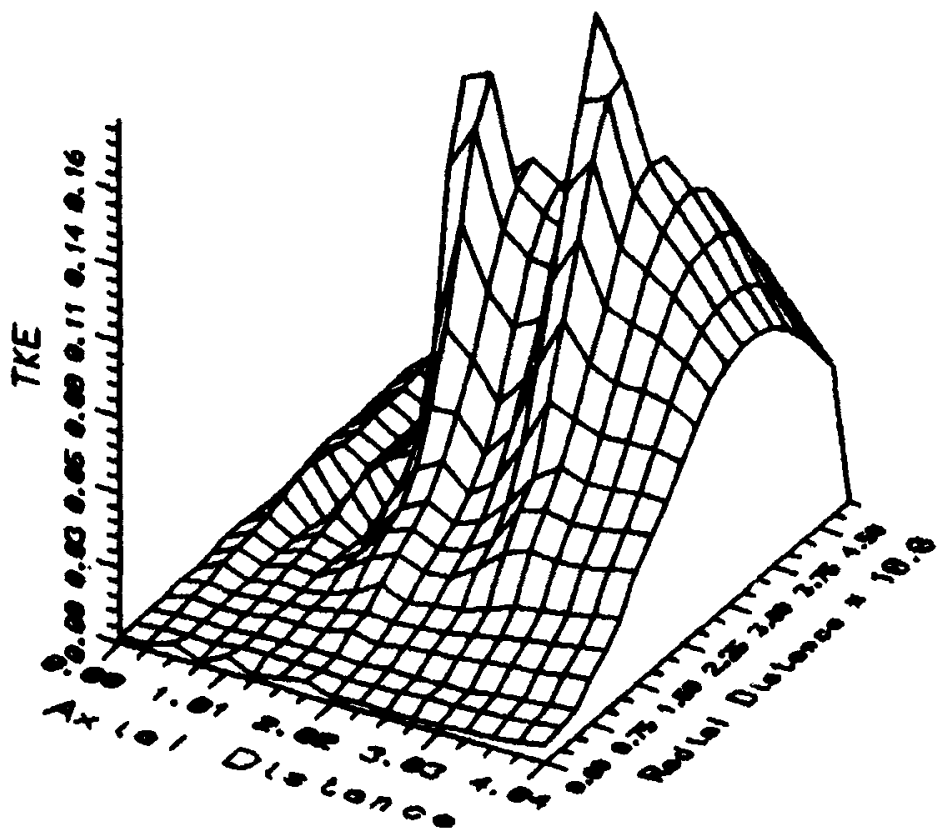

Figure 10. 3-D plot of turbulent kinetic energy for $\mathrm{PR}=10$ and $\theta=10$. 


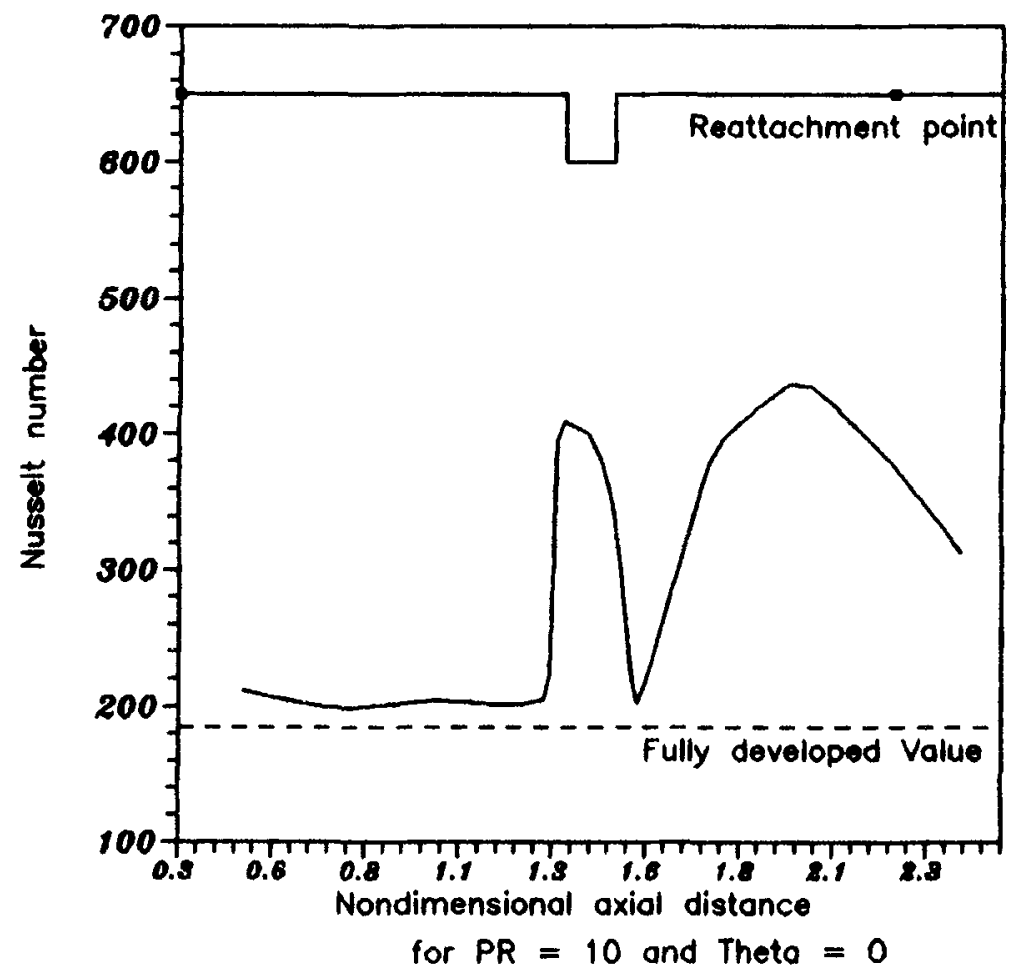

Figure 11. Nusselt number peaks observed for $P R=10$.

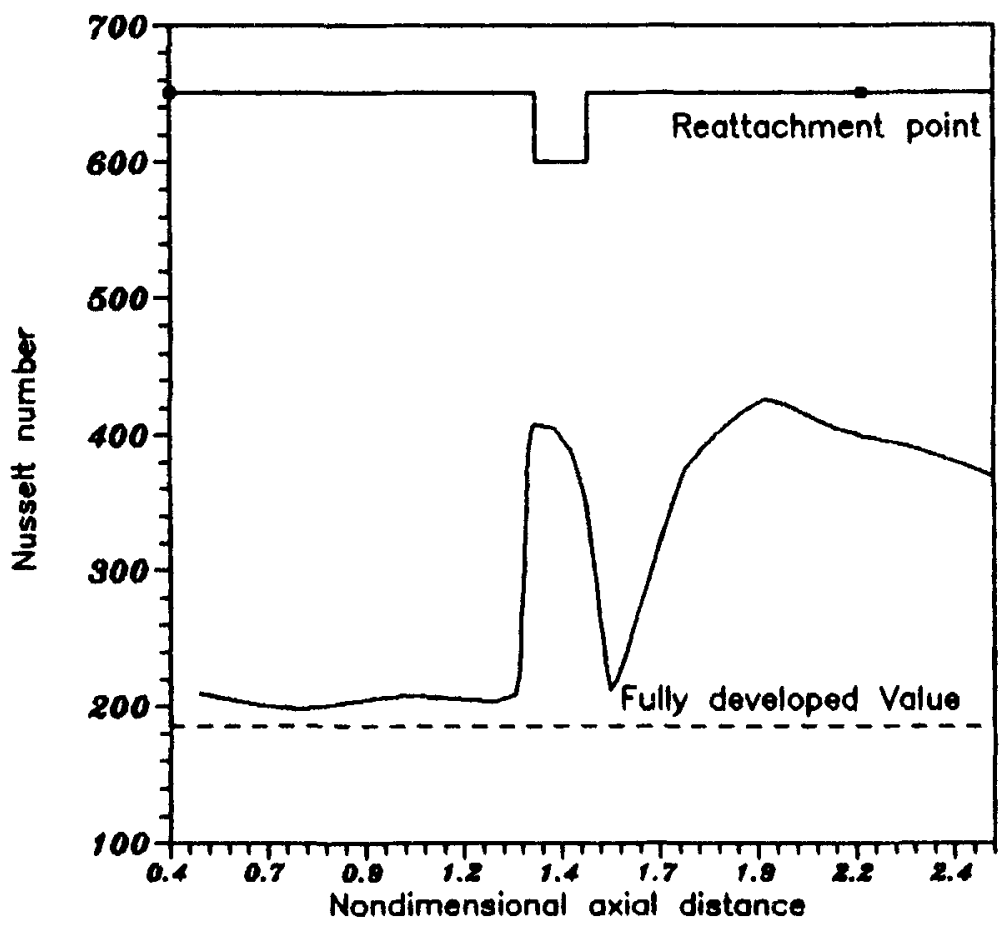

Figure 12. Nusselt number peaks observed for $P R=15$. 
The conventional way of estimating the heat transfer augmentation is given by Rabas (1989) as

$$
\eta=\frac{\text { ratio of average heat transfer coefficient }}{\text { ratio of pressure drop per unit length }} .
$$

Geometry without turbulence promoters is taken as the reference for comparison. Table 5 gives the efficiencies for different cases for Pr number $=0.722$. Comparisons are made with smooth channel flow keeping all other conditions such as length, $R e$ and inlet profiles the same. The results for smooth channel are also obtained by the same code using the $k-\varepsilon$ model.

Then $\eta$ reduces with pitch ratio and increases with rib wall angle inclination. The average Nusselt number is reduced with pitch ratio and rib wall angle inclination. The average Nusselt number varies between 1.75 and 2.0 times the smooth channel Nusselt number. Liou et al (1990) reported that relative to a smooth duct, the presence of periodic ribs at two opposite walls yields up to $2 \cdot 2$-fold increase in fully developed average Nusselt number.

(ii) Conclusions - The pressure drop in channels with ribs reduced with rib wall inclination. There is no significant drop in average heat transfer coefficient. All the trends in local Nusselt number and reattachment lengths are predicted. The improvement in heat transfer augmentation varies between 30 and 39 percent for various step-side inclinations when compared with the straight ribs, the maximum being for $P R=10$ and $\theta=35^{\circ}$. It is also observed that the maximum average Nusselt number is achieved for a pitch ratio of 10 .

4.1c Flow through a plane diffuser-Comparison between flow with and without inlet velocity distortions: Diffusers are widely used for converting kinetic energy to pressure energy. A proper understanding of flows in a diffuser will lead to a better design of fluid machines with improved efficiency. The flow in a diffuser is highly complex and simple analytical solutions are not available to treat such turbulent flows under adverse pressure gradients. Most of the numerical predictions of diffuser flows are based on boundary layer approximations and solutions are obtained by either solving the integral equations or by solving the modelled differential equations.

It is well known that certain types of inlet velocity distortions affect the efficiency of the diffuser in converting kinetic energy to pressure energy. Hence the influence

Table 5. Comparison of $\eta$ values.

\begin{tabular}{lrcrc}
\hline$\theta$ & PR & $\overline{\mathrm{Nu}} / \mathrm{Nu}_{s}$ & $\Delta P / \Delta P_{s}$ & $\eta$ \\
\hline & 5 & 1.894 & 9.28 & 0.2041 \\
0 & 10 & 1.851 & 11.41 & 0.1622 \\
& 15 & 1.795 & 12.40 & 0.1448 \\
& 5 & 1.952 & 7.65 & 0.2552 \\
35 & 10 & 1.918 & 9.76 & 0.1965 \\
& 15 & 1.867 & 9.92 & 0.1882 \\
& 5 & 1.737 & 6.47 & 0.2685 \\
50 & 10 & 1.845 & 8.17 & 0.2258 \\
& 15 & 1.770 & 9.11 & 0.1943 \\
\hline
\end{tabular}


of inlet velocity distortions on diffuser performance needs detailed investigation. It has been observed that with certain types of velocity distortions at the inlet of the diffuser, the efficiency decreases, while with certain other types of distortions, the efficiency improves when compared to the uniform velocity distribution at the inlet.

The prediction of diffuser flows with uniform inlet velocity is fairly well established. Lai \& coworkers report the inadequacy of the wall-function approximations for diffuser flows. Since the high Reynolds number versions of the standard two-equation models are based on the local equilibrium assumption and use some kind of wall function to handle the near wall flow, they are not suitable for diffuser flow calculations. In order to account for the anisotropic behaviour near a wall some kind of a low Reynolds number version of a turbulence model capable of resolving the flow up to the wall should be considered.

Hah (1983), used the finite difference method to predict turbulent flows in planar, conical and annular diffusers with inlet swirl and inlet velocity distortion. With the swirling velocity component, the flow is pressed towards the wall by centrifugal force and the wall boundary layer is less likely to separate even if the diffuser divergent angle is large, and a higher pressure recovery coefficient is observed. Inlet velocity distortion is obtained by putting a thin ring outside the wall boundary layer at the inlet for a diffuser of total expansion angle of $16^{\circ}$. The separation near the wall is suppressed when the inlet flow is altered, resulting.in more favourable pressure gradient along the wall and higher diffuser performance is thus obtained. Hoffman (1982) also altered the inlet velocity and reported an improvement in the overall diffuser efficiency.

The present investigation is aimed at studying the improvement in diffuser performance by distorting the inlet velocity profile. Chitambaran (1978) conducted experiments for a plane diffuser with a divergent angle of $4^{\circ}$, both with and without inlet distortions. No separation is reported in the diffuser. The present results are compared with the experiments conducted by Chitambaran (1978). A low Reynolds number version of the $k-\varepsilon$ model is used to close the momentum equations.

(i) Results and discussion - Figures 13 and 14 give the stream lines for Case 1 (flow without inlet velocity distortion) and Case 2 (flow with distortion) respectively. The stream lines in Case 2 are slightly packed together in the first half of the diffuser. This is due to the distortion in inlet velocity profile. In the second half of the diffuser

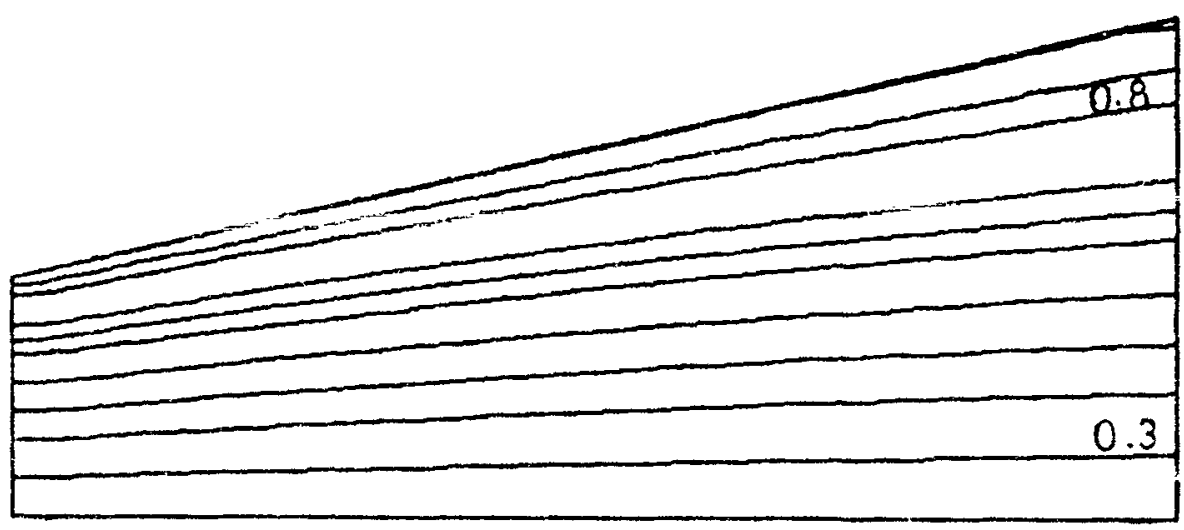

Figure 13. Streamline plot for flow through diffuser without inlet distortion. 


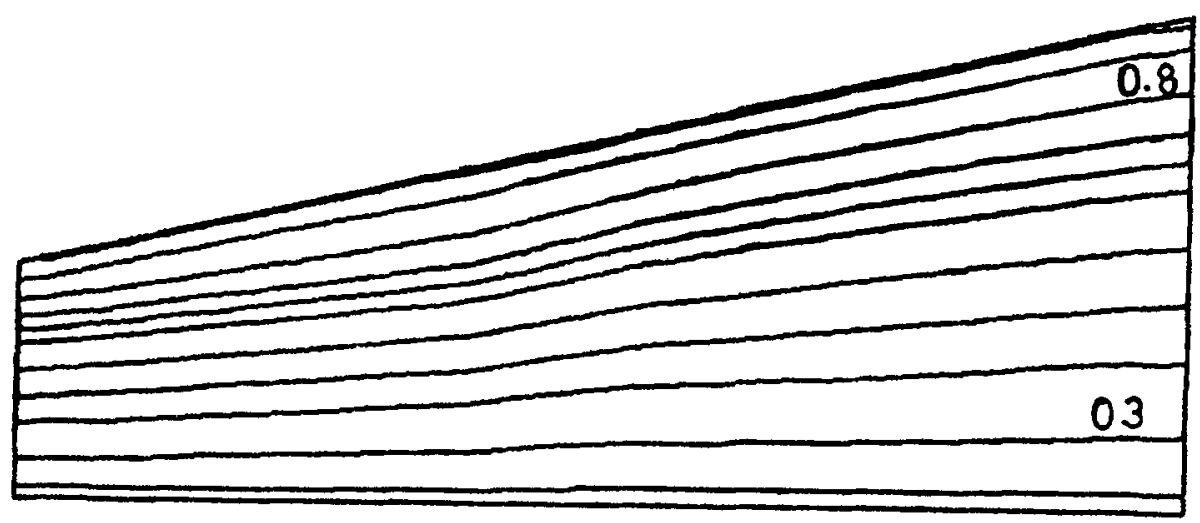

Figure 14. Streamline plot for flow through diffuser with inlet distortion.

the distortion effect dies out and the stream lines become similar to that of the Case 1 . No separation is predicted as reported in the experiments. Figures 15 and 16 compare the predicted velocity profiles at three downstream sections with experiments for Case 1 and Case 2. For Case 1 the prediction is good. In the second half of the diffuser the maximum velocity is slightly less than experiments for Case 2 . In most of the sections the near-wall prediction is good and the maximum error in the prediction of velocity profiles is 4.1 percent. The distortion in the velocity profile is predicted very well.

The inlet condition for $\varepsilon$ in Case 1 is calculated using (21) where $D$ is taken as the width of the diffuser. The inlet condition for Case 2 is calculated using the following formula.

$$
\varepsilon_{\text {in }}=\left(C_{\mu}^{3 / 4} k^{3 / 2}\right) /(\kappa y),
$$

where $\kappa$ is a constant in Prandtl mixing length and is equal to 0.4 .

The turbulent kinetic energy profiles for Case 1 are given in figure 17. For Case 2 the profiles are compared with experiments in figure 18. In the first half of the diffuser the prediction is good and in the second half the peak value in the profile is slightly under-predicted. The peak values of turbulent kinetic energy are much higher when compared with free stream turbulence. There is marginal increase in the intensity of free stream turbulence, towards the exit of the diffuser. The occurrence of the peak is very close to the wall near the inlet of the diffuser and the peak is shifted away from the wall with distance in the stream-wise direction.

In the calculation of $\varepsilon_{\text {in }}$ from (23), if the normal wall distance is taken from the

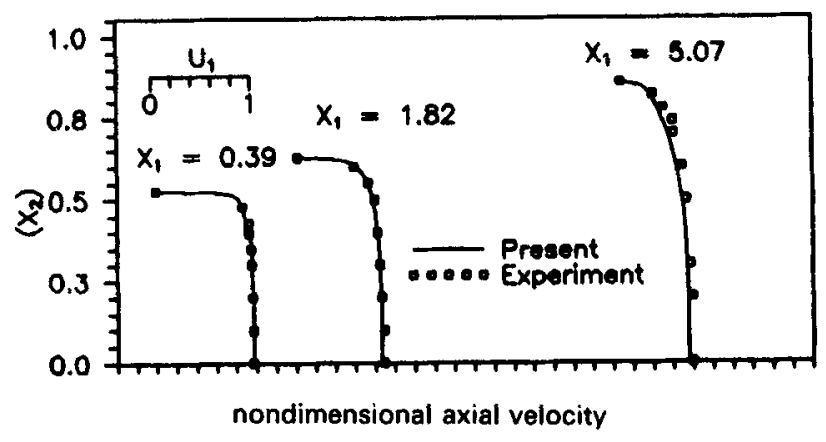

Figure 15. Comparison of axial velocity for flow through diffuser without inlet distortion at different axial locations. 


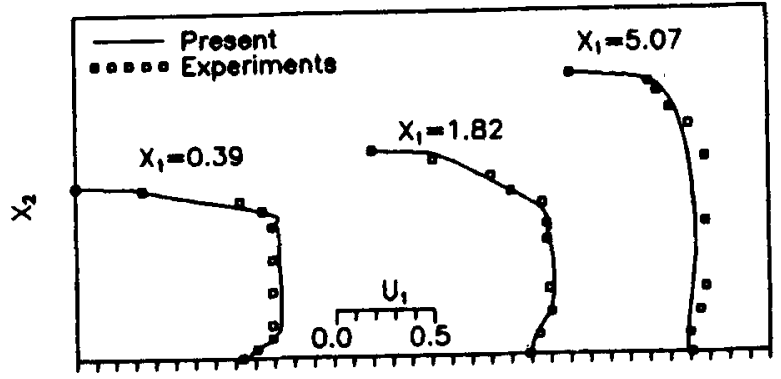

Axial Velocity
Figure 16. Comparison of axial velocity for flow through diffuser with inlet distortion at different axial locations.

wall of the diffuser the peak value in the $k$ profile in Case 2 near the axis due to the inlet distortion is under-predicted. This could be due to the fact that the aerofoil also acts as a wall. For the calculation of $\varepsilon_{\text {in }}$ the normal wall distance in (23) is slightly modified. The tip of the aerofoil is considered to be a wall and the normal wall distance is taken as the minimum distance from the diffuser wall and the aerofoil tip. This makes the normal distance of nodes near the axis less than that of the distance from the wall and results in higher $\varepsilon$ values near the axis. As a result the peak value in the $k$ profile has increased and compares well with the experiments in the initial portion of the diffuser.

The prediction of pressure distribution is very vital for the diffuser. Figures 19 and 20 show the comparison of pressure recovery percentage with axial distance. It agrees very well with the experiments. Pressure recovery factor is defined as the ratio of actual pressure recovered to the theoretical pressure recovery possible. The theoretical pressure recovery possible is calculated using one-dimensional Bernoulli's equation between inlet and outlet sections of the diffuser. In Case $2,81 \%$ of the possible kinetic energy has been converted into pressure energy. In Case 2 it is $88 \%$. Figure 21 compares the pressure recovery factor with experiments and the agreement is good. Figure 22 shows the variation of pressure recovery factor for Case 2 . It can be seen that $61 \%$ of the possible pressure recovery takes place in the first half of the diffuser in Case 1 and $66 \%$ in the first half in Case 2. The remaining 39 and 34\% recovery takes place in the second half of the diffuser for Case 1 and Case 2 respectively. An improvement of $8.8 \%$ in pressure recovery has been obtained in Case 2 from Case 1.

Figure 23 and 24 show the comparison of friction factors for Case 1 and Case 2. The maximum error in this comparison is about $6.82 \%$. For Case 2 the comparison in the first half is better when compared to the second half.

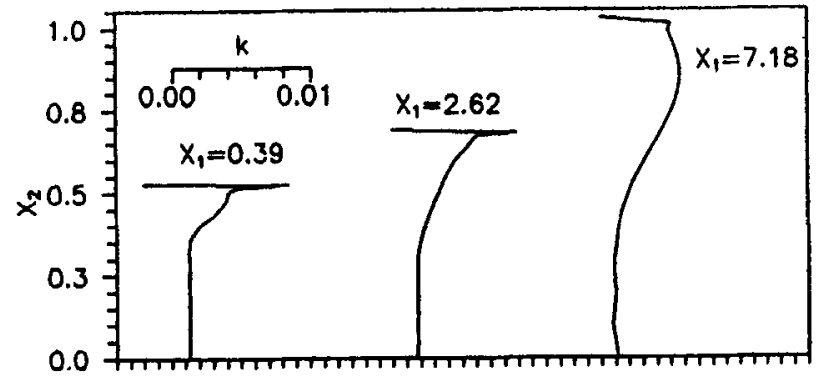

Turbulent Kinetic Energy
Figure 17. Variation of turbulent kinetic energy for flow through diffuser without inlet distortion at different axial locations. 


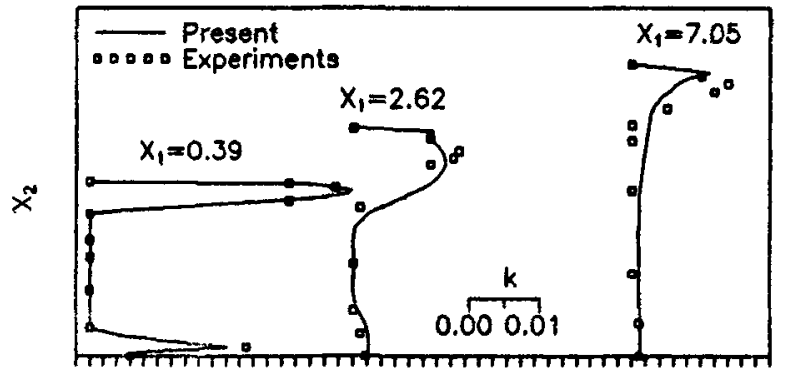

Turbulent Kinetic Energy
Figure 18. Comparison of turbulent kinetic energy for flow through diffuser with inlet distortion at different axial locations.

(ii) Conclusions - The inlet velocity distortion created by the aerofoil resulted in $8.8 \%$ more pressure recovery in a two-dimensional plane diffuser with divergent angle $4^{\circ}$. The general purpose finite element code based on low Reynolds number $k-\varepsilon$ equation predicted the mean velocity profiles, kinetic energy profiles and pressure recovery reasonably well and provides useful guidance and information for the advanced design.

\subsection{3-D Laminar flows}

4.2a Flows in rectangular ducts: Numerical solutions of 3-D laminar flows in ducts

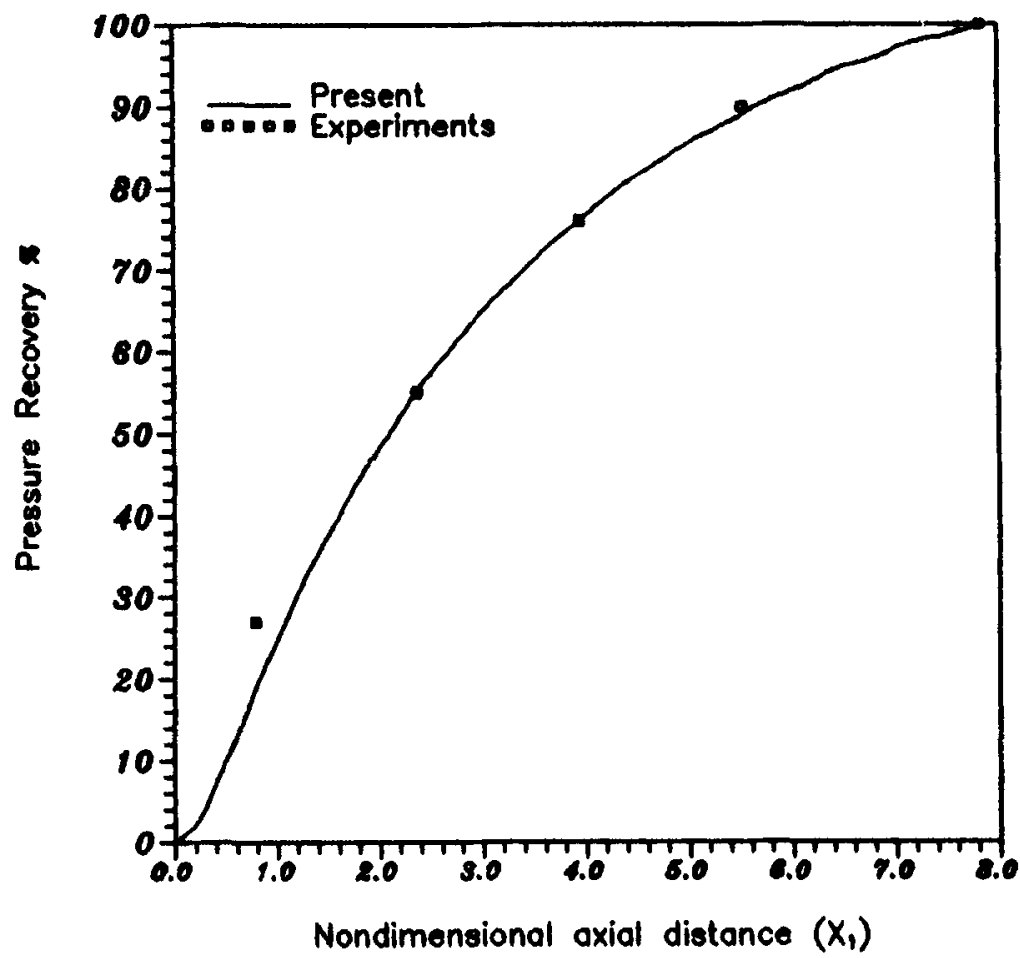

Figure 19. Comparison of pressure recovery percentage for flow through diffuser without inlet velocity distortion. 


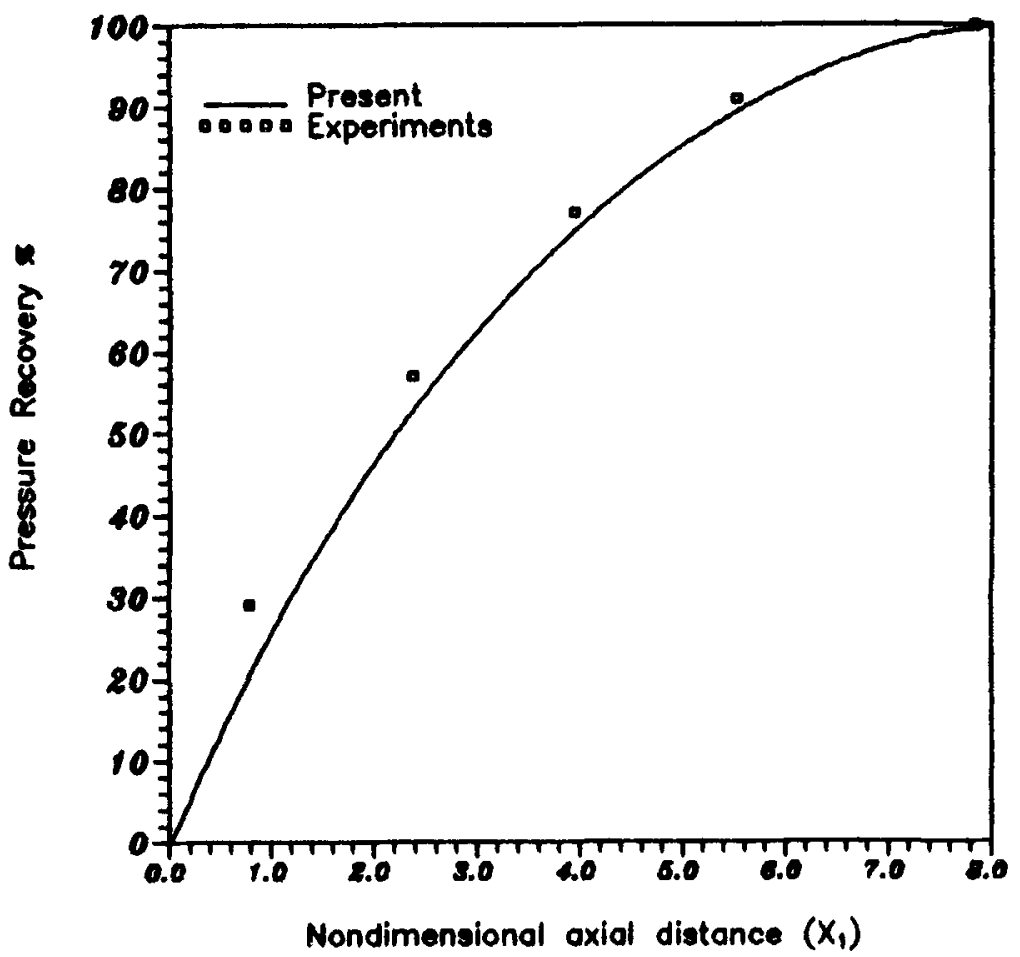

Figure 20. Comparison of pressure recovery percentage for flow through diffuser with inlet velocity distortion.

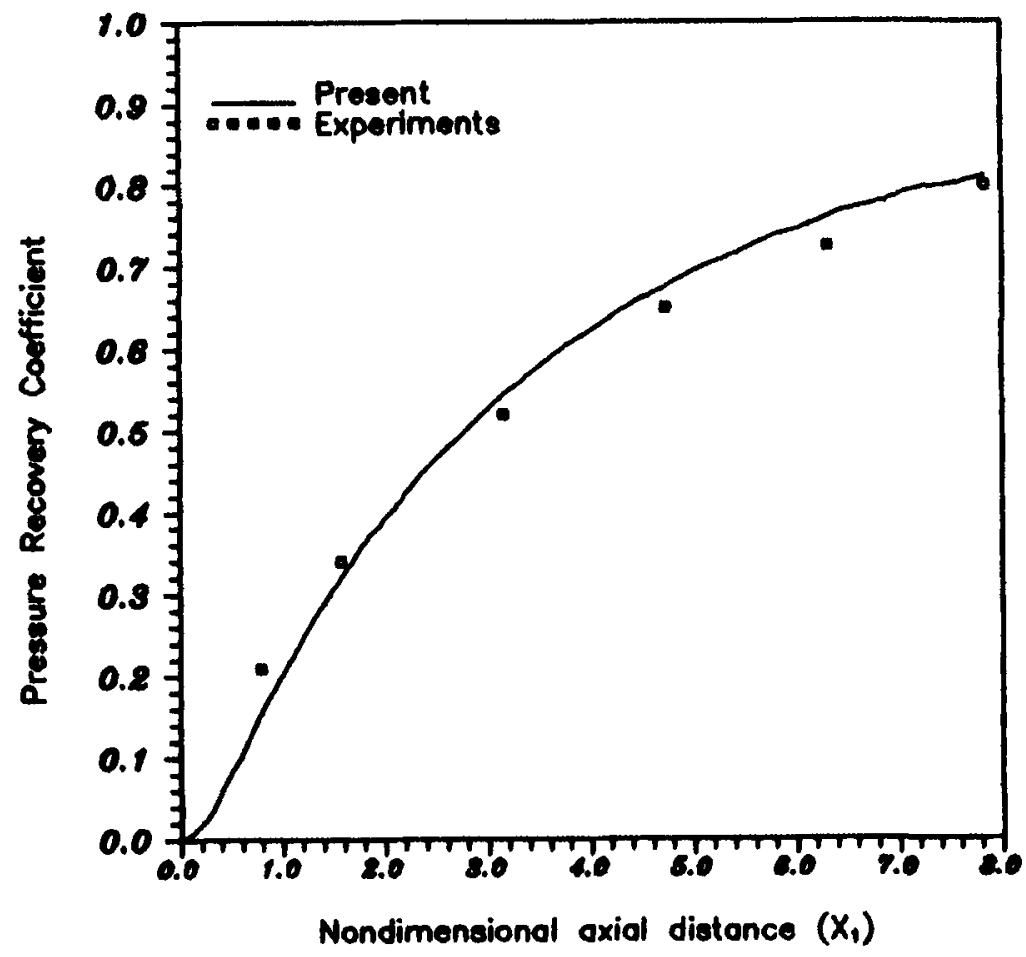

Figure 21. Variation of pressure recovery coefficient for flow through diffuser without inlet velocity distortion. 


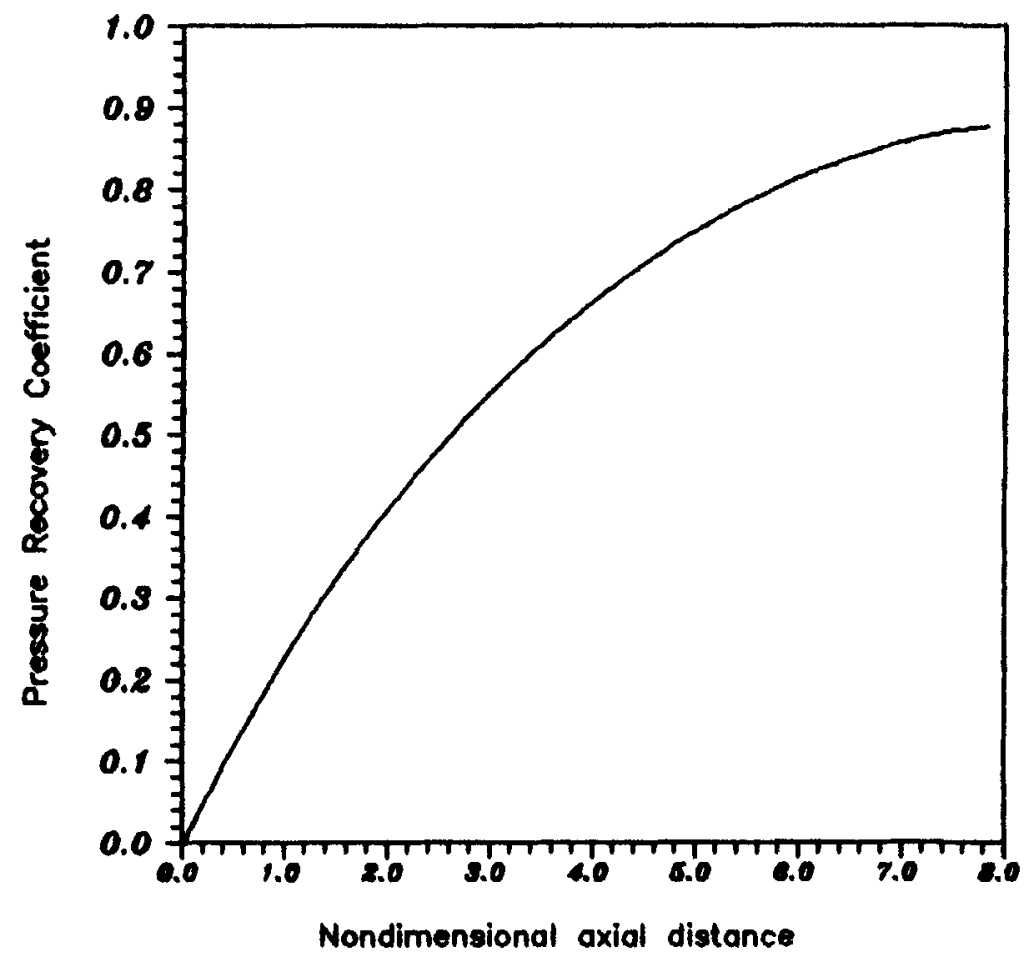

Figure 22. Comparison of pressure recovery coefficient for flow through diffuser with inlet velocity distortion.

is well developed with parabolic procedures. Patankar and Spalding (Firziger 1987) presented an accurate and economical parabolic method for calculating heat and mass, and momentum transfer in three-dimensional flows. A finite element procedure for the prediction of laminar forced convection in three-dimensional parabolic flows is presented by Nonino et al (1988). Local Nusselt number variations are presented and the results are compared with the correlations. Godbole (1975) used a penalty function approach for solving flow at a very low Re number.

In the present study, the complete Navier-Stokes equations are solved. Flow in rectangular ducts is solved for aspect ratios $\alpha^{*}=0 \cdot 5,0 \cdot 75,1 \cdot 0$. Aspect ratio $1 \cdot 0$ is for a square duct. Heat is treated as a scalar in forced convection problems. The temperature field has no influence on the flow field. The Navier-Stokes' and the energy equations are solved as an uncoupled system.

(i) Geometry and boundary conditions - Due to symmetry, only a quarter of the duct is solved. All the lengths are non-dimensionalised with the hydraulic diameter of the duct. No-slip boundary conditions are assumed on the walls, symmetric conditions at the axis and also that there should not be any flow across the axis plane. Hence the flow velocity perpendicular to the axis plane is specified as zero on the axis. Traction-free boundary conditions are specified at the exit. Pressure is specified as zero at the exit. Inlet velocity is specified as unity. The hydrodynamic developing length for ducts is approximately 0.01 times the Reynolds number for the square and rectangular ducts. Different lengths are taken for different $R e$ to save computing time. However in the case of the rectangular ducts, the same length is taken for all the $\operatorname{Re}$ 


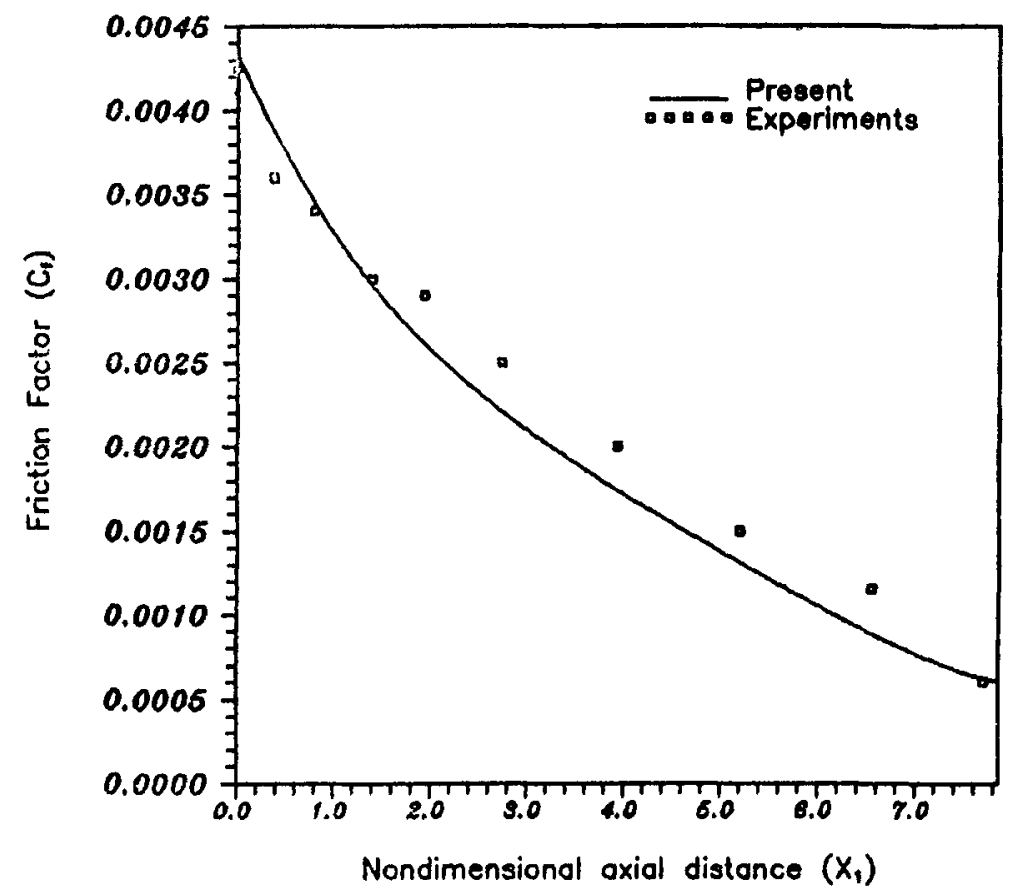

Figure 23. Comparison of friction factor for flow through diffuser without inlet velocity distortion.

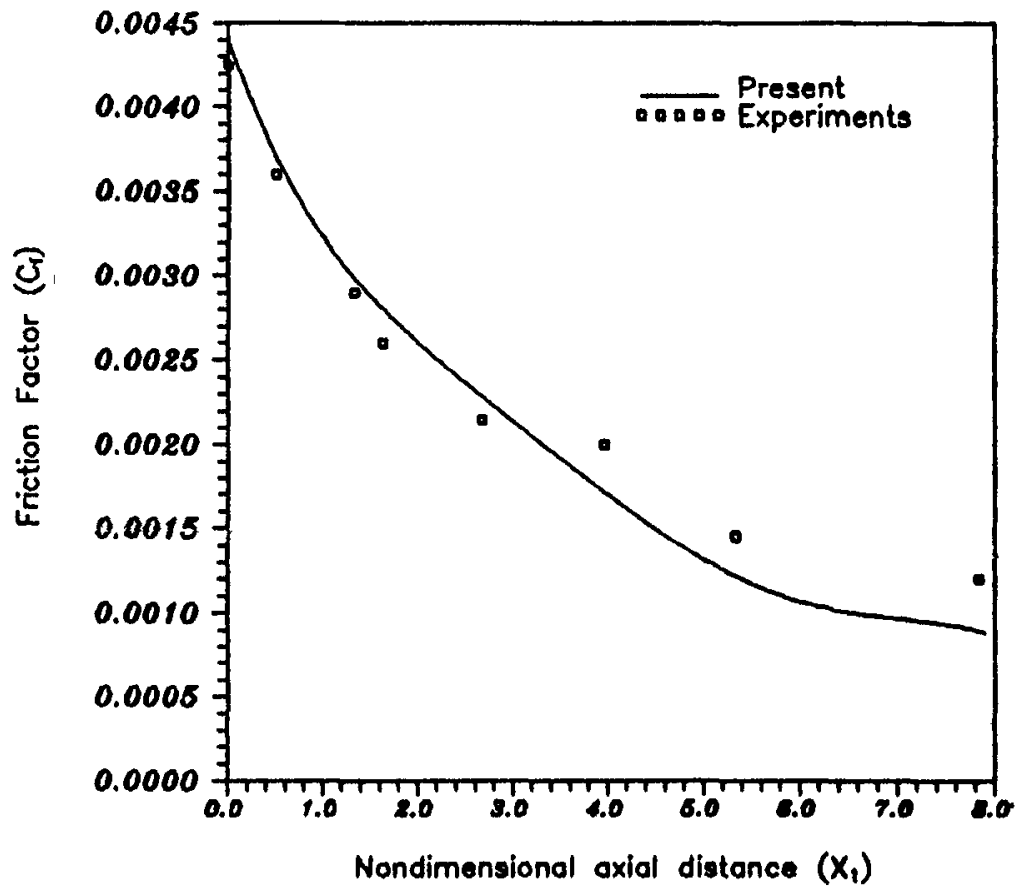

Figure 24. Comparison of friction factor for flow through diffuser with inlet velocity distortion. 
numbers solved i.e. 50,100 and 200 .

The domain is divided into tetrahedral elements. Initially the domain is divided into cuboids. Each cuboid can be divided into either five or six tetrahedral elements without introducing any new nodes. However if the cuboid is divided into five tetrahedrae, each cuboid has to be divided in a different manner. In order to avoid this, each cuboid is divided into six tetrahedra. This does not increase the memory requirement since no new nodes are introduced. Also the increase in computational time is negligible.

(ii) Results and discussion-Figure 25 shows the comparison with experiments of velocity profiles of square duct. Grid independence tests were conducted with $11 \times 11$, $13 \times 13$ and $15 \times 15$ grids. The variation from $13 \times 13$ in the velocity profile for $15 \times 15$ is very little. Unlike in 2-D flows, the size of the mesh goes up rapidly even by increasing the mesh size by one node in each section. The bandwidth also goes up rapidly. In order to keep the size of the problem and the computational time required at a reasonable level all the further calculations are carried out with a grid size of $13 \times 13$.

Aspect ratio of elements in each section is approximately adjusted to one. The mesh is irregular and at least three nodes are placed within the boundary layer. Also it is observed that it is better to refine the mesh in each section rather than to have more sections in the flow direction for better prediction of fully developed velocity profile, Nusselt number and friction factor. It is also observed that as the mesh is refined the development of the flow is slow. Table 6 shows the comparison of $U_{\max } / U_{m}$ and the hydrodynamic length for square ducts for different values of $\operatorname{Re}$. The hydrodynamic developing lengths for square ducts given by Srinivas (1994) are in good agreement with experiments.

Even though the cell Peclet number is larger, stability is taken care of by the time step. All the convective and diffusive terms of Navier-Stokes equations are multiplied with the time step. The maximum time step permissible varies from mesh to mesh. As the mesh becomes finer the time step allowable becomes smaller.

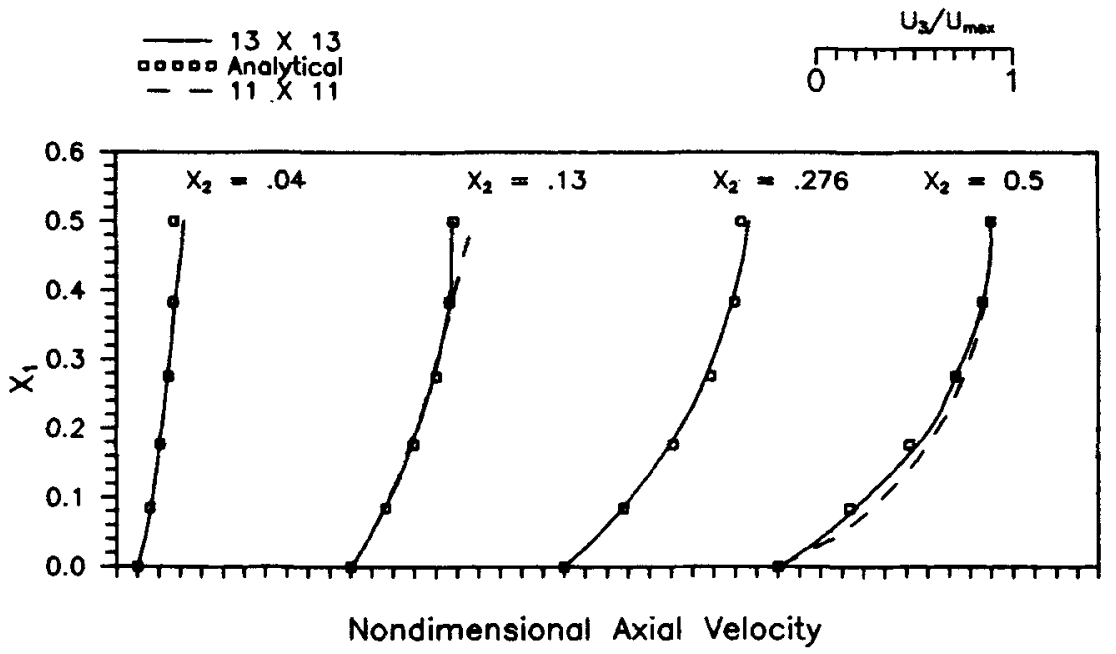

Figure 25. Comparison of fully developed axial velocity profiles for flows through square ducts, at different locations. 
Table 6. Comparison of maximum velocity and hydrodynamic length for flow through a square duct for different values of Re.

\begin{tabular}{|c|c|c|c|c|}
\hline \multirow[b]{2}{*}{$\operatorname{Re}$} & \multirow{2}{*}{ 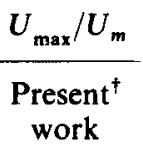 } & \multicolumn{3}{|c|}{$L_{h y}$} \\
\hline & & $\begin{array}{l}\text { Present } \\
\text { work }\end{array}$ & Dalton* & Han* \\
\hline 50 & $2 \cdot 11$ & 4.90 & $4 \cdot 5$ & 3.75 \\
\hline 100 & 2.03 & $10 \cdot 10$ & $9 \cdot 0$ & $7 \cdot 50$ \\
\hline 200 & 1.97 & $19 \cdot 60$ & $18 \cdot 0$ & $15 \cdot 0$ \\
\hline 500 & 1.96 & $43 \cdot 10$ & 45.0 & $37 \cdot 50$ \\
\hline
\end{tabular}

+Compared with the fully developed value 2.090

*Shah \& London (1978)

The wall derivatives are evaluated using curve fitting techniques. It is observed that 4-point fit is adequate to predict the Nusselt numbers and friction factors. It is not advisable to go beyond 5-point fit, as the higher order polynomial fits are well known for their lack of accuracy and their tendency to manifest kinks and oscillations in the fitted curve. The derivatives are evaluated at all the boundary nodes and the curve is integrated for the evaluation of Nusselt number and friction factor.

Table 7 shows the prediction of fully developed Nusselt numbers for constant temperature boundary condition for various $\operatorname{Re}$ and for various $\alpha^{*}$.

Figures 26 and 27 show the variation of non-dimensionalised pressure drop for different $\operatorname{Re}$ for $\alpha^{*}=0.5$ and 0.75 . It can be seen that no chequer-board oscillations are present in the pressure field prediction.

The skin friction coefficient and the Nusselt number are often used to present the results in a concise manner. Figure 28 shows the variation of friction factor for square ducts for different Re. Figures 29 and 30 show the variation of bulk temperature and Nusselt number for different Pr numbers. The maximum error in the prediction of Nusselt number and friction factor is about $3 \%$. Figure 31 shows the isotherms in fully developed section.

(iii) Conclusions - The problems solved reveal many aspects of the developed tool. The results indicate that the present predictions are good. The pressure field shows no chequer-board splitting. A four-point fit is adequate to calculate the wall derivatives.

Table 7. Comparison of Nusselt numbers for different $\operatorname{Re}$ for square ducts and rectangular ducts.

\begin{tabular}{lrccc}
\hline & & \multicolumn{3}{c}{ Nusselt number } \\
\cline { 3 - 5 } S. No & $\operatorname{Re}$ & $\alpha^{*}=1.0$ & 0.50 & 0.75 \\
\hline 1 & 50 & 2.980 & 3.58 & 3.11 \\
2 & 100 & 2.967 & 3.62 & 3.07 \\
3 & 200 & 2.910 & 3.64 & 3.05 \\
\hline
\end{tabular}

Fully developed value for $\alpha^{*}=1.00$ is $2 \cdot 996,0.75$ is 3.140 , 0.50 is 3.91 (as given in Shah \& London 1978) 


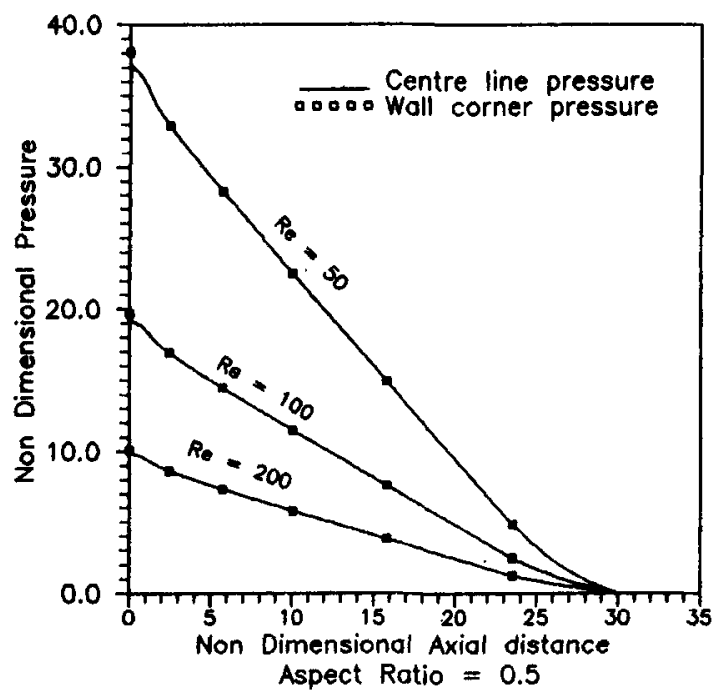

Figure 26. Pressure drop in flow through rectangular duct for different $\operatorname{Re}$ for $\alpha^{*}=0.5$.

\section{Closure}

The present method offers a cost and storage effective algorithm for prediction of 2-D and 3-D internal flows. It requires a minimum of CPU time and storage space, as no large matrix is being solved. During the early period of the transient behaviour, the flow field and the thermal field evolve rapidly and the time step has to be very small. As time progresses, the rate of convergence becomes slower, i.e., the difference between the values of any field variable for two successive iterations become smaller, at which state the time step can be progressively increased. Thus a judicious selection of time step effects a significant reduction in storage requirement and CPU time. At the same time, accuracies comparable to finite difference methods are achieved. All the present results have been obtained by running the finite element code on an AT 486 machine.

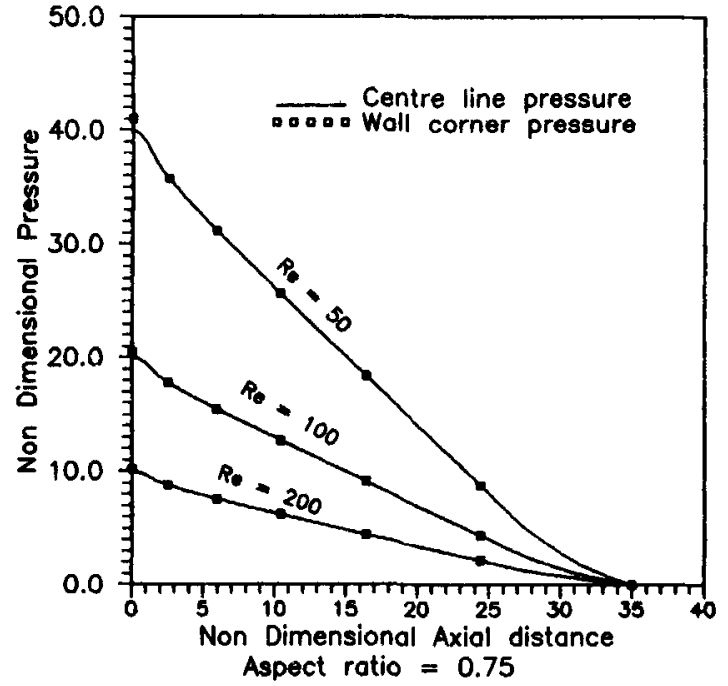

Figure 27. Pressure drop in flows through rectangular ducts for different $\operatorname{Re}$ for $\alpha^{*}=0.75$. 


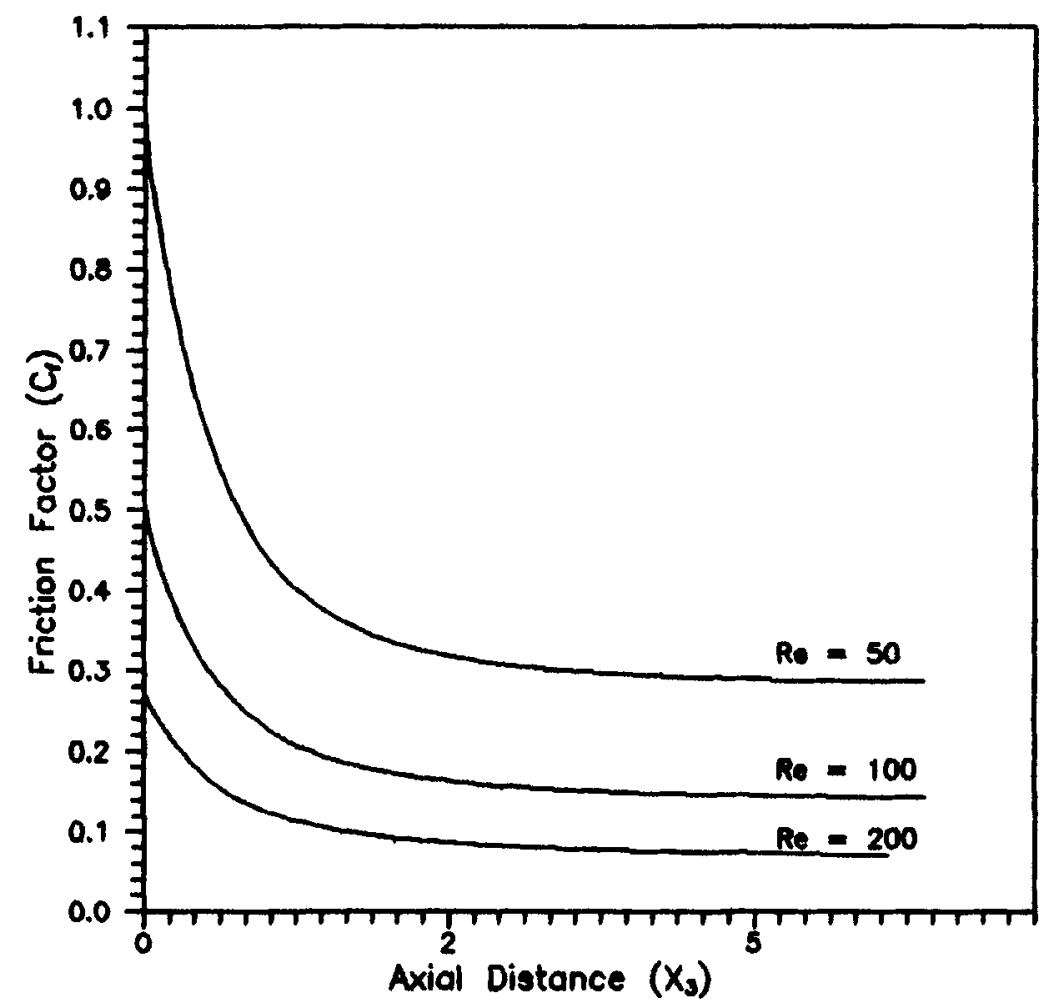

Figure 28. Variation of friction factor for flows through square ducts for different Re.

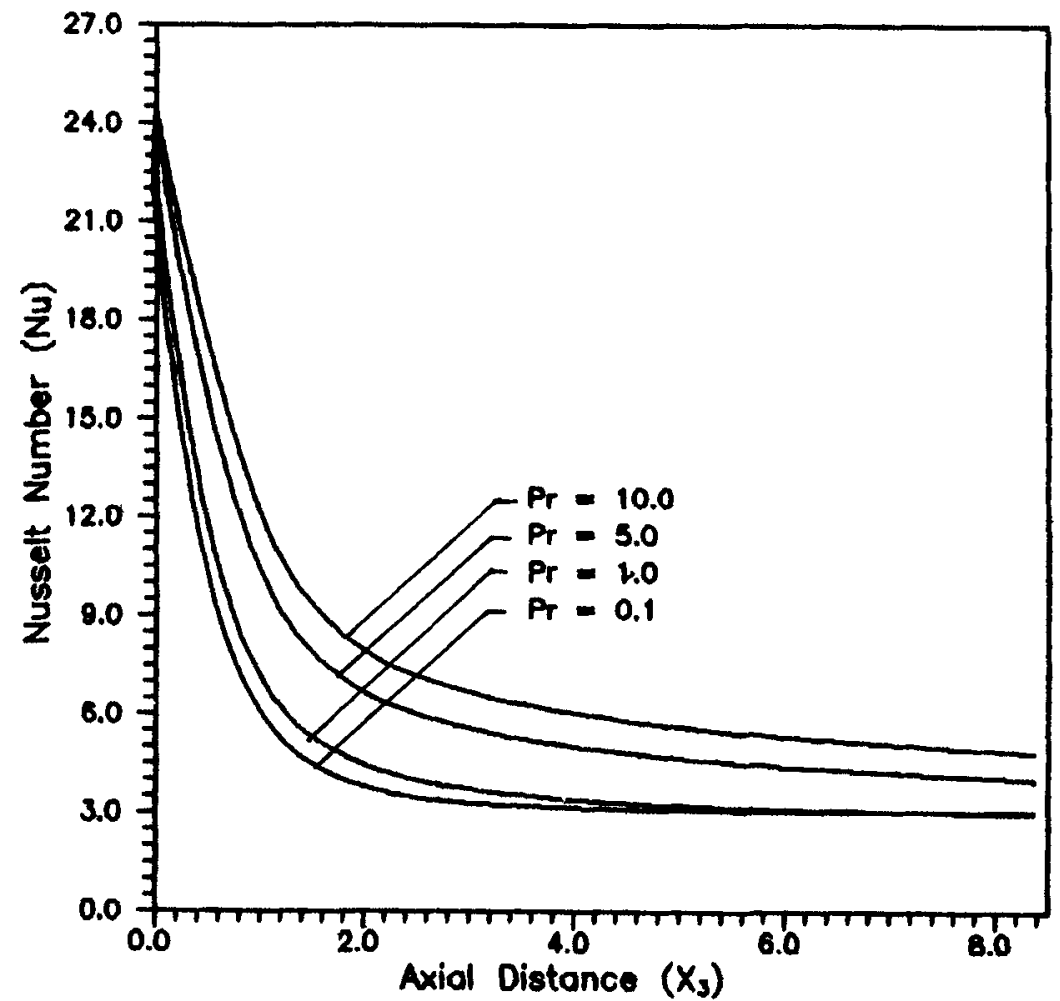

Figure 29. Variation of Nusselt number for flow through square duct for different Pr. 


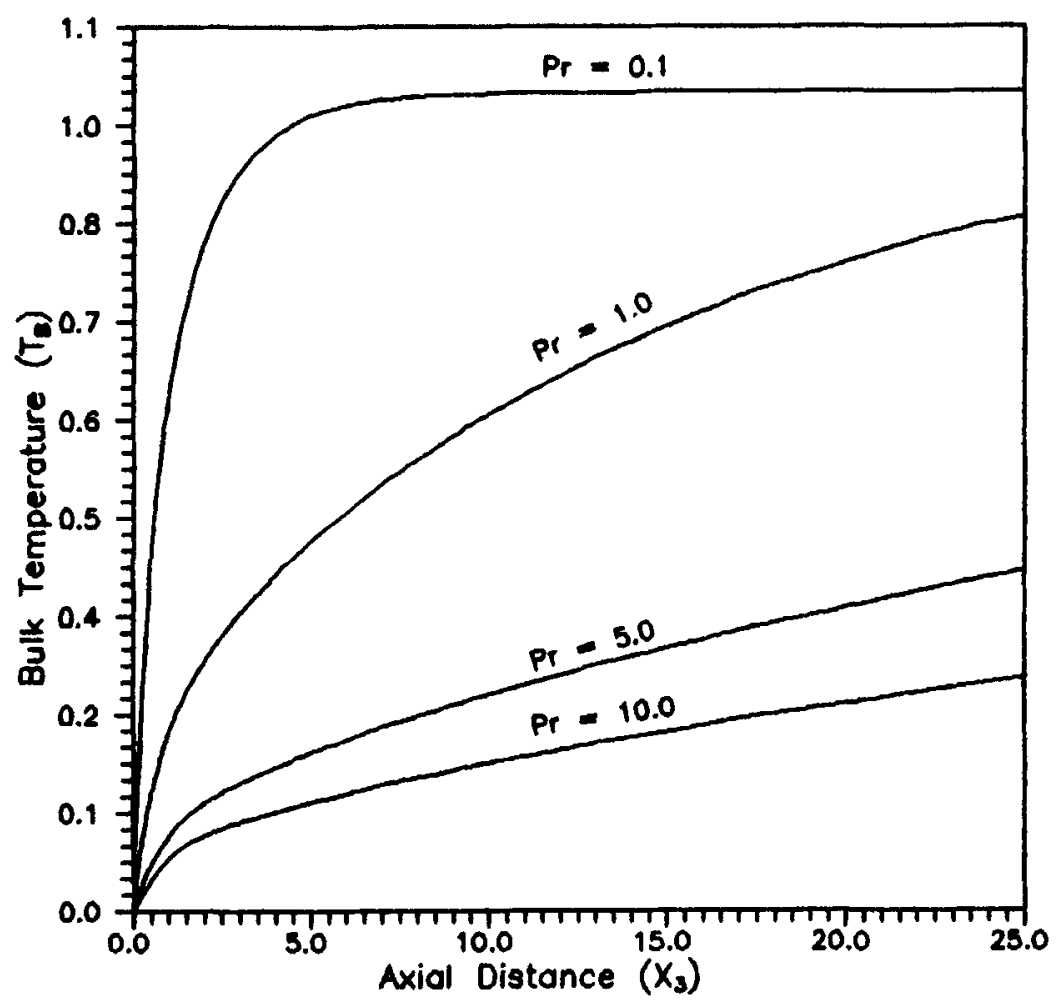

Figure 30. Variation of bulk temperature flow through square duct for different Pr.

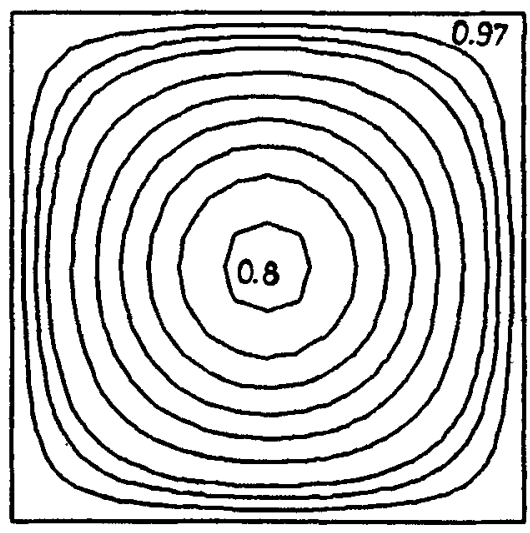

Figure 31. Isothermal plot in an axial crosssection of square duct.

\section{List of symbols}

$\begin{array}{ll}C_{f} & \text { friction factor; } \\ C_{\mu}, C_{\varepsilon 1}, C_{\varepsilon 2} & \text { turbulence model constants; } \\ f_{\mu}, f_{1}, f_{2} & \text { turbulence model functions; } \\ f & \text { frequency; }\end{array}$


HR

$k$

l

$L_{\text {ref }}$

LR

$n, n+1$

$\mathrm{Nu}$

$\mathrm{Nu}$

$\mathrm{Nu}_{s}$

NML

$P$

$\Delta P$

$\Delta P_{s}$

PML

$P_{i}$

$\mathrm{Pe}$

Pr

PR

Re

$t$

$\Delta t$

$T_{*}$

$U_{1}$

$U_{3}$

$U_{\text {ref }}$

$U_{*}$

$V$

VEV

$X_{1}$

$X_{3}$

$\mathrm{X}_{\mathrm{R} 1}$

$X_{R 2}$

$y$

$\alpha$

$\alpha_{T}$

$\varepsilon$

$\varepsilon_{i n}$

$v$

$v_{T}$

$\eta$

$\rho$

$\sigma_{k}, \sigma_{\varepsilon}$

$\theta$

high Reynolds version of turbulence model;

turbulence kinetic energy

mixing length;

Reference length for non-dimensionalization; low Reynolds version of turbulence model;

at $n$th and $(n+1)$ th time step;

Nusselt number;

average Nusselt number for ribbed channel;

Nusselt number of smooth channel;

Nikuradse mixing length;

mean component of pressure;

pressure drop per unit length of ribbed length;

pressure drop per unit length of smooth channel;

Prandtl mixing length;

pitch of the ribs as shown;

Peclet number $=$ Re.Pr;

Prandtl number;

pitch ratio, $P_{i} / H$;

Reynolds number;

dimensionless time;

time step;

Wall heat flux temperature (used in high Re versions);

flow direction velocity for 2-D problems;

flow direction velocity for 3-D problems;

reference velocity;

friction velocity (used in high $\mathrm{Re}$ version);

pseudo velocity in Eulerian velocity correction method;

Van Driest effective viscosity model;

flow direction for 2-D problems;

flow direction for 3-D problems;

non-dimensional reattachment length (with rib height) after first rib;

non-dimensional reattachment length (with rib height) after second

rib;

normal wall distance;

thermal diffusivity;

turbulent thermal diffusivity;

turbulent kinetic energy dissipation;

inlet value of $\varepsilon$;

momentum diffusivity;

turbulent momentum diffusivity;

heat transfer augmentation efficiency;

density;

turbulence model constants for diffusion of $k$ and $\varepsilon$;

rib wall inclination.

\section{References}

Acharya S, Dutta S, Myrum A, Baker R S 1993 Periodically developed flow and heat transfer in a ribbed duct. Int. J. Heat Mass Transfer 36: 2069-2082 
Autret A, Grandotto M, Dekeyser I 1987 Finite element computation of a turbulent flow over a two dimensional backward facing step. Int. J. Numer. Methods Fluids 7: 89-102

Benim A C, Zinser W 1985 Investigation into the finite element analysis of confined turbulent flows using a $k-\varepsilon$ model. Comput. Methods Appl. Mech. 51: 507-523

Bradshaw P et al 1981 Engineering calculation methods for turbulent flows (London: Academic Press)

Caretto L S et al 1972 Two numerical methods for 3-D boundary layers. Comput. Methods Appl. Mech. Eng. 1: 39-57

Chitambaran V C 1978 Some studies on the structure of incompressible turbulent flow in a two-dimensional diffuser with inlet velocity distortions, $\mathrm{Ph} D$ thesis, Indian Institute of Technology, Madras

Curr R M, Sharma D, Tatchell 1972 Numerical predictions of some 3-D boundary layets in ducts Comput. Methods Appl. Mech. Eng. 1: 143-158

Deissler R G 1988 Turbulent solutions of the Navier-Stokes equations. Encyclopedia of fluid mechanics (Houston, TX: Gulf) vol. 6, chap. 29

Donea J, Ginliani S, Laval H, Quartapele 1982 Finite element solution of unsteady NavierStokes equations by fractional step method. Comput. Methods Appl. Mech. Eng. 30: 53-73

Ferziger J H 1987 Simulation of incompressible turbulent flows. J. Comput. Phys. 69: 1-48

Gresho P M, Sani R L 1987 On pressure boundary conditions for the incompressible Navier-Stokes equations. Int. J. Numer. Methods Fluids 7: 1111-1145

Gresho P M et al 1981 Solution of the time dependent 3-D incompressible Navier-Stokes equation via FEM. In Proc. Int. Conf. on Numerical Methods in Laminar and Turbulent flows (eds) C Taylor et al, UK

Godbole P N 1975 Creeping flow in rectangular ducts by finite element method. Int. J. Numer. Methods Eng. 727-731

Hah C 1983 Calculation of various diffuser flows with inlet swirl and inlet distortions effects. AIAA J. 21: 1127-1133

Haines A B 1982 Turbulence modelling - Report of a working party. Aeronaut. J. 86: 269-277

Han J C, Glicksman L R, Roshenow W M 1978 An investigation of heat transfer and friction factor for rib roughened surface. Int. J. Heat Mass Transfer 27: 1143-1155

Hoffmann J A 1982 Effects of free stream turbulence on diffuser performance. J. Fluids Eng., ASME 103: 104-110

Hussaini M Y, Zang T A 1987 Spectral methods in fluid dynamics. Annu. Rev, Fluid Mech. 19: $339-367$

Hutton A G, Smith R M 1987 The computation of turbulent flows of industrial complexity by finite element method-Progress and prospects. In Finite elements in fluids (eds) R H Gallagher et al (New York: John Wiley) 7: 289-310

Johnson R W, Launder B E 1982 Discussions on the calculation of turbulent heat transport down stream of an abrupt pipe expansion. Numer. Heat Transfer 5: 493-495

Lakshminarayana B, Kirtley K R, Warfield M 1989 Computational techniques and validation of 3-dimensional viscous turbulent codes for internal flows. Sādhanā 14: 59-91

Lam C K G, Bremhorst K 1981 A modified form of $k-\varepsilon$ model for predicting wall turbulence. J. Fluids Eng. 103: 456-460

Launder B E 1982 A generalized algebraic stress transport modelling. AIAA J. 20: 436-437

Launder B E 1984 Numerical computation of convective heat transfer in complex turbulent flows: Time to abandon wall functions. Int. J. Heat Mass Transfer 27: 1485-1491

Launder B E 1988 On the computation of convective heat transfer in complex turbulent flow. J. Heat Transfer 110, 1112-1128.

Liou T M, Chang Y, Huang D W 1990 Experimental and computational study of turbulent flows in a channel with two pairs of turbulence promoters in tandem. J. Fluids Eng. 112: $302-310$

Lumley J L 1983 Turbulence modelling. ASME J. Appl. Mech. 50: 1097-1103

Markatos M C 1988 Computer simulation techniques for turbulent flows. In Encyclopedia of fluid mechanics (Houston, TX: Gulf) vol. 6, chap. 28

Martinuzzi R, Pollard A 1989 Comparative study of turbulence models in predicting turbulent pipe flow. Part I: Algebraic stress and $k-\varepsilon$ models. AIAA J. 27: 29-36

Mellor G L, Herring J H 1973 A survey of mean turbulent filled closure models. AIAA J. 11: 590-599 
Michelic M, Wingerath K 1988 Numerical solution of free and forced convection bulk flows. In Encyclopedia of fluid mechanics (Houston, TX: Gulf) vol. 6, chap. 35

Morgan K et al 1987 Investigation of mixing length and two-equation turbulence models utilizing the finite element method. Appl. Math. Modelling 1: 395-400

Murphy J D 1988 Turbulence modelling. In Encyclopedia of fluid mechanics (USA: Gulf) vol. 6, chap. 28

Nallasamy M 1987 Turbulence models and their applications to the prediction of internal flows: A review. Comput. Fluids 15: 151-194

Nonino C, Del Guidice, Comini G 1988 Laminar forced convection in 3-D duct flows. Numer. Heat Transfer 13: 451-466

Patankar S V 1988 Recent developments in computational heat transfer. ASME J. Heat Transfer 110: 1037-1045

Pletcher R H 1988 Progress in turbulent forced convection. ASME J. Heat Transfer 110: $1129-1144$

Rabas T J 1989 Selection of energy efficient enhancement geometry for single phase turbulent flows inside tubes. ASME Proc. of 1989 Natl. Heat Conf., HTD vol. 108, pp. 193-204

Ravikumaur S G 1988 Finite element analysis of convective heat transfer and heat exchangers. $\mathrm{Ph} \mathrm{D}$ thesis, Indian Institute of Technology, Madras

Ravisankar M S 1992 Finite element analysis of turbulent flows with heat transfer. M S thesis, Indian Institute of Technology, Madras

Reddy J N 1982 Penalty finite element analysis of 3-D Navier-Stokes equations. Comput. Methods Appl. Mech. Eng. 35: 87-106

Reynolds W C 1978 On calculation of turbulent flows. In Turbulence (ed.) P Bradshaw (New York: Springer-Verlag) chap. 5

Rodi W 1982 Examples of turbulent flow in smooth pipe. Appl. Sci. Res. 28: 872-879

Rodi W 1984 Turbulence models and their applications to hydraulics - State of art review. Intl. Assos. Hydraulic Res., Delft

Shah R K, London A L 1978 Laminar flow forced convection in ducts. Advances in heat transfer: Supplement 1 (New York: Academic Press)

Shih T M 1985 A literature survey on numerical heat transfer. Numer. Heat Transfer 8: 1-24

Shih T M 1987 A literature survey on numerical heat transfer. Numer. Heat Transfer 11: 1-29

Shih T M 1989 A literature survey on numerical heat transfer. Numer. Heat Transfer 15: 1-39

Smith R M 1984 A practical method of two-equation modelling using finite elements. Int. $J$. Numer. Methods Fluids 4: 321-336

Srinivas M 1994 Finite element analysis of internal flows with heat transfer. $\mathrm{Ph} \mathrm{D}$ thesis, Indian Institute of Technology Madras

Taylor C et al 1977 A numerical analysis of turbulent flow in pipes. Comput. Fluids 5: 191-203

Taylor C, Harper J J, Hughes T G, Morgan K 1981 An analysis of developing turbulent flow in a circular pipe by the finite element method. In Proc. Numer. Methods Laminar and Turbulent flows (eds) Baker et al (Swansea: Pineridge)

Utnes T 1988 Two-equation $(k-\varepsilon)$ turbulence computations by the use of a finite element model. Int. J. Numer. Methods Fluids 8: 965-975 